\title{
CRIME POTENTIAL MODELLING: A GIS BASED METHOD USING
} WEIGHTS-OF-EVIDENCE,

\author{
by \\ Joseph Alexander Fraser Moffatt \\ A thesis submitted in partial fulfillment of the \\ requirements for the degree of \\ Master of Arts (Geography and \\ Environmental Studies)
}

CARLETON UNIVERSITY

(C) May 2005 


$\begin{array}{ll}\begin{array}{l}\text { Library and } \\ \text { Archives Canada }\end{array} & \begin{array}{l}\text { Bibliothèque et } \\ \text { Archives Canada }\end{array} \\ \begin{array}{l}\text { Published Heritage } \\ \text { Branch }\end{array} & \begin{array}{l}\text { Direction du } \\ \text { Patrimoine de l'édition }\end{array} \\ \begin{array}{l}\text { 395 Wellington Street } \\ \text { Ottawa ON K1A ON4 } \\ \text { Canada }\end{array} & \begin{array}{l}\text { 395, rue Wellington } \\ \text { Ottawa ON K1A ON4 } \\ \text { Canada }\end{array}\end{array}$

Yourfile Votre référence ISBN:

Our file Notre reterence ISBN:

NOTICE:

The author has granted a nonexclusive license allowing Library and Archives Canada to reproduce, publish, archive, preserve, conserve, communicate to the public by telecommunication or on the Internet, loan, distribute and sell theses worldwide, for commercial or noncommercial purposes, in microform, paper, electronic and/or any other formats.

The author retains copyright ownership and moral rights in this thesis. Neither the thesis nor substantial extracts from it may be printed or otherwise reproduced without the author's permission.

\section{AVIS:}

L'auteur a accordé une licence non exclusive permettant à la Bibliothèque et Archives Canada de reproduire, publier, archiver, sauvegarder, conserver, transmettre au public par télécommunication ou par l'Internet, prêter, distribuer et vendre des thèses partout dans le monde, à des fins commerciales ou autres, sur support microforme, papier, électronique et/ou autres formats.

L'auteur conserve la propriété du droit d'auteur et des droits moraux qui protège cette thèse. $\mathrm{Ni}$ la thèse ni des extraits substantiels de celle-ci ne doivent être imprimés ou autrement reproduits sans son autorisation.
In compliance with the Canadian Privacy Act some supporting forms may have been removed from this thesis.

While these forms may be included in the document page count, their removal does not represent any loss of content from the thesis.

\section{1+ \\ Canada}

Conformément à la loi canadienne sur la protection de la vie privée, quelques formulaires secondaires ont été enlevés de cette thèse.

Bien que ces formulaires aient inclus dans la pagination, il n'y aura aucun contenu manquant. 


\section{Abstract \\ CRIME POTENTIAL MODELLING: A GIS BASED METHOD USING WEIGHTS- OF-EVIDENCE}

This thesis was undertaken to evaluate the utility, effectiveness and accuracy of the GIS-based weights of evidence prediction model for the spatial prediction of residential break and enter crime in the City of Ottawa. The data-driven predictive weights of evidence (WofE) model was applied against six specific land uses of the urban environment as identified in the environmental criminology literature, including known occurrences of break and enters, in order to generate maps that could identify where future occurrences of residential break and enter might be located. Using the Arc-WofE extension written for the ArcView 3.2 GIS software package, a series of "crime potential maps" were generated that successfully indentified small areas of high potential (in the order of 60 to $95 \%$ probability) and were successful in placing future break and enter occurrences in these areas of high potential. 


\section{TABLE OF CONTENTS}

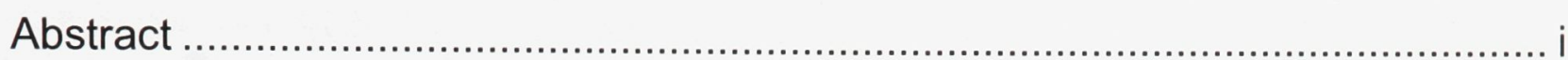

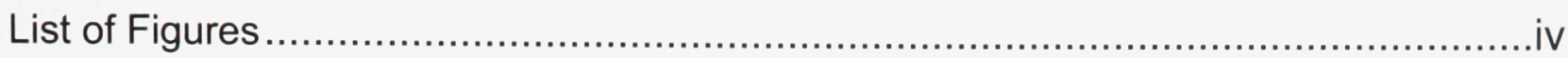

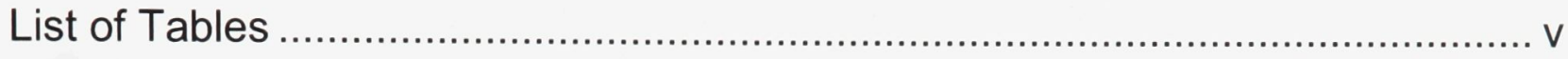

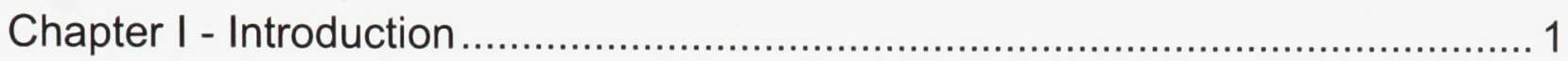

Problem Statement/Hypothesis ............................................................... 1

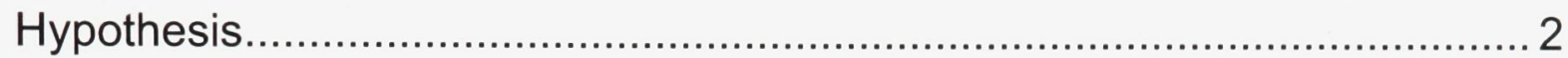

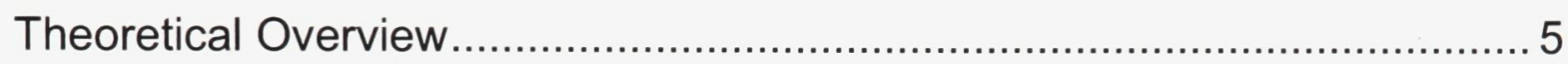

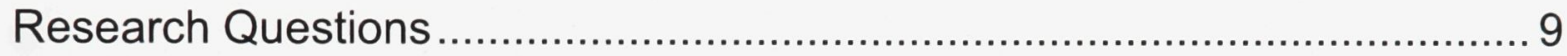

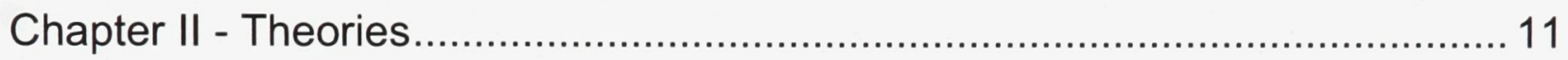

The Discipline of Environmental Criminology ........................................ 11

Three Key Theories Supporting Crime Potential Modelling ........................ 23

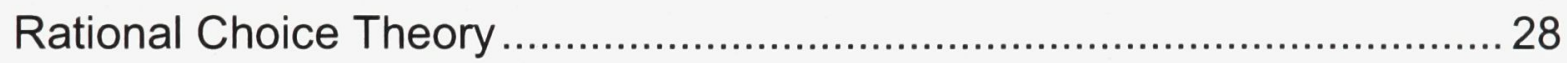

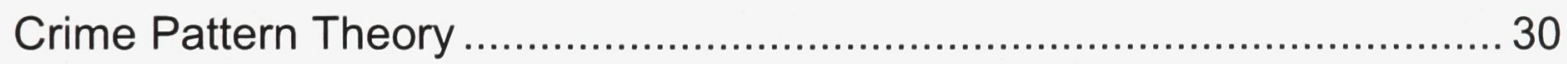

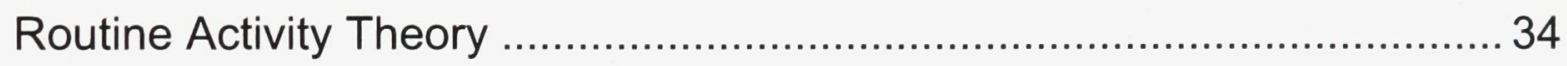

Chapter III - Crime Potential Modelling ........................................................... 41

The Ecology and Spatial Prediction of Crime .......................................... 41

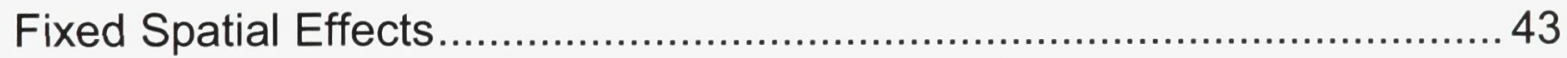

Weights-of-Evidence (WofE) and Crime Potential Modelling (CPM) .......... 47

Spatial Prediction Models - the Weights-of-Evidence Model ..................... 48

Fixed Spatial Effects as Inputs into the WofE Model .................................. 57

Chapter IV - Research Design and Methodology ........................................... 62

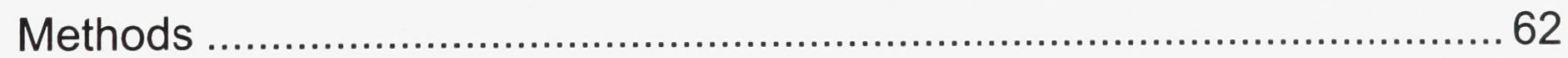

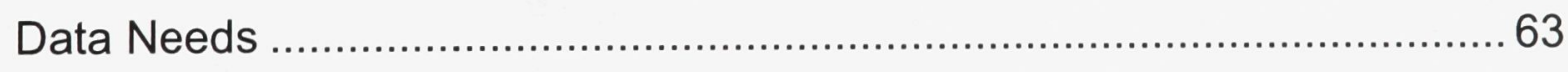

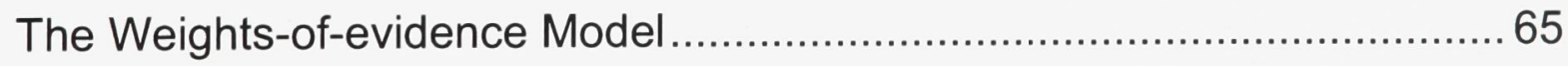

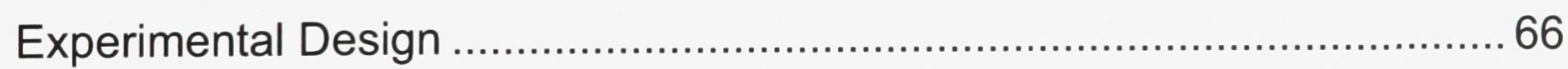

Chapter V - Results of Analysis ............................................................. 71

Initial Exploratory Spatial Data Analysis .............................................. 71

Optimum Sample Size Analysis/Temporal Analysis ............................... 80 


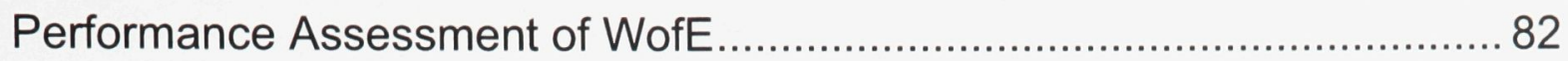

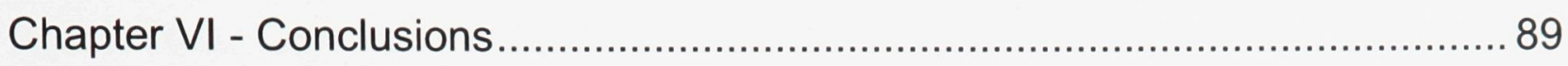

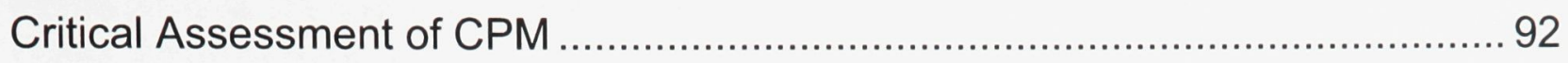

Appendix A - Wofe Results Data Tables....................................................... 94

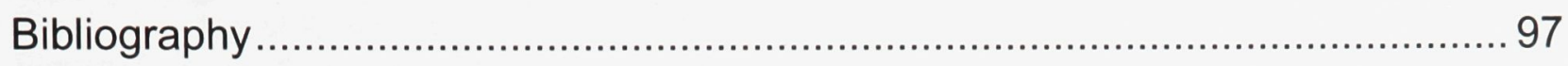




\section{List of Figures}

Figure 1. Geometry of Crime (after Brantingham and Brantingham, 1981).

Figure 2 Crime Triangle (after Cohen and Felson, 1979)

Figure 3 Map Algebra

Figure 4 - Venn diagram of Conditional Probabilities

Figure 5 Illustration of $\mathrm{W}+$ and $\mathrm{W}$ - for 48 classes plotted with $\mathrm{sC}$

Figure 6 - Map of Study Area

Figure 7 - Long Term B\&E Trends in Ottawa

Figure 8 Proximity to Commercial Land Use / W+, W- , C and stud C chart 76

Figure 9 Proximity to Main Roads / W+, W- , C and stud C chart $\quad 76$

Figure 10 Proximity to 4 Node Intersections / W+, W- , C and stud C chart $\quad 77$

Figure 11 Proximity to Vacant Land/ Parkland / W+, W- , C and stud C chart

Figure 12 Proximity to Urban Trails / W+, W- , C and stud C chart 78

Figure 13 Recreational Land Use/ W+, W-, C and StudC chart 78

Figure 14 - MaxPP Output $\quad 80$

Figure 15 CPM Study Area and Training Data Locations for Week 202000 Test 84

Figure 16 Study Area and CPM Predictions for Week $202000 \quad 85$

Figure 17 Study Area Showing Residential Land Use $\quad 85$

Figure 18 Study Area Showing Residential Land Use areas where CPM map > 50\% PP 86

Figure 19 CPM and Week 202000 Test Data Locations 86

Figure 20 Post Probabilities of Week 202000 Test Locations 87 


\section{List of Tables}

\section{Table 1 Sampling Framework}

Table 2 Statistics for each layer of evidence

Table 3 Overall W+ and W- values for each layer of evidence (full year 2000)

Table 4 Maximum Probability of points in week being tested (8-week training data)

88

Table 5 Maximum Probability of CPM for test period (8-week training data) 


\section{Chapter I - Introduction}

\section{Problem Statement/Hypothesis}

Developments in the study of crime over the last sixty years have encompassed the notion that the occurrence of crime occurs neither randomly nor uniformly in time and space (Brantingham and Brantingham, 1991). If crime is not random, then does it follow that there is something about crime that is systematic? If crime is not uniformly distributed, what effects does the organization of space in any given area have on the occurrence of crime? Until the 1980s, the study of crime examined offender-based criminality, specifically from a sociological perspective. Research conducted between 1900 and 1980 indicated that the "systemization" of criminality was fraught with a number of critical concerns. In particular, these include: the confusion of the interpretation of criminal residence and crime location; the erroneous assumption of even distribution of physical, social and criminal phenomena within the spatial study units; the assumption of ecological fallacy; and, incorrect or incomplete data from official sources (Brantingham and Brantingham, 1981). During the 1980s, however, a shift took place in the study of crime that looked to criminal events with a focus on the geography and ecology of crime. This shift in perspective stimulated the notion that crime was a function of motivation and opportunity coming together at the same time at the same place. Concurrently, three specific motivational theories were being developed that accounted for offender behaviour and decision-making that includes the offender's use of time and space. A theoretical stance exists today that embodies the notion of the ecological aspects of crime and that the location of crime is a 
function of an offender's structured knowledge of the environment in which the offender exists in and moves through. This structured knowledge is shaped, in part, by the offender's perception of the environmental cues that exist for a variety of places and spaces that the offender is aware of. These cues provide the offender with critical information that discriminate between good criminal opportunities and bad criminal risks (Brantingham and Brantingham, 1981). If a criminal's environment can be looked at as the "urban landscape", the "systemization" of the crime event can look at what sorts of features of this landscape can provide the criminal with the appropriate cues that indicate that a particular target is a good opportunity. A number of spatial analyses of crime were conducted after Brantingham and Brantingham's seminal publication of Environmental Criminology in 1981 that looked specifically at various land use types and their relationships with crime, most frequently property crime. Many of these studies showed strong positive relationships between certain types of land use and the occurrence of property crime. Likewise, research done in the areas of routine activity theory, rational choice theory and crime pattern theory are major contributors to this vein of thought.

\section{Hypothesis}

So, if crime is not random, and if, according to the theories, there are systematic, but non-uniform spatial configurations that might influence where a motivated offender may choose to commit a crime, it is my hypothesis that these systems can be modeled in an aggregate manner to not only provide some sort of 
understanding as to why crime occurs where it does, but where it may occur in the future.

From a descriptive perspective, it is certainly valuable to know what has happened in the past, but what can be done to infer what may happen in the future? While there is a distinct trend in the crime analysis community in the research and development of a variety of sophisticated temporal predictive models for crime volume, there is little research that addresses the spatial prediction of crime in an inferential manner ${ }^{1}$. It is intended that this thesis will provide an initial step in addressing that gap. An opportunity also exists to examine the utility of spatial predictive models that can be used for day-to-day tactical crime analysis in a law enforcement setting to enhance operational effectiveness in the ability to solve certain types of crime. However, this action is intended as a potential by-product of the successful outcome of this research as opposed to a distinct goal within the scope of research project.

The first goal of this research project to identify, in an applied manner, those systematic land use configurations (dubbed "fixed spatial effects") that, according to the relevant theories, can influence where offenders choose to commit residential break and enters. The second goal is to aggregate those individual effects in a GIS-based weights-of-evidence model in order to generate an output

\footnotetext{
${ }^{1}$ Recent research by researchers at the Jill Dando Institute of Crime Science notwithstanding. Bowers, Johnson and Pease (2004) "Prospective Hotspotting: The Future of Crime Mapping". British Journal of Criminology 44(5)
} 
that isolates areas that have a greater potential for being targets of crime within a given study area. 


\section{Theoretical Overview}

Quantitative studies of crime carried out as early as 1833 by criminologists (seminal studies by Guetelet and Querry in France, most significantly), sociologists and geographers alike have supported the notion that crime is neither random nor uniform (Burgess, 1925; White, 1932; Shaw and McKay, 1942; Harries, 1980; Brantingham and Brantingham, 1991; Felson, 1997 and many others). Many of the spatial analyses of crime conducted in the fields of criminology, sociology and geography between 1940 and 1980 embodied the positivistic methods popular in the days of the Quantitative Revolution ${ }^{2}$ in that links were made between social and demographic variables and the occurrence of crime and delinquency (Cohen and Felson, 1969; Herbert, 1975; Newman, 1980; Shaw and McKay, 1942/1969). Significant bodies of work in addressing the ecology of crime appeared in the 1970s: Crime Prevention through Environmental Design (Jeffrey, 1971) and Defensible Space (Newman, 1982). These works addressed the specific role of the design and human use of space and place as elements that either attracted or repelled crime and disorder. Aside from Jeffrey's and Newman's work, research conducted in the applied quantitative manner was criticized in the 1980 s as "suffering from severe logical problems" (Brantingham and Brantingham, 1981, p. 11), the most significant problem being one of ecological fallacy. The traditional thrust of the spatial analysis of crime was one of "criminality" - the study of the motivation of the

\footnotetext{
${ }^{2}$ Following Peter Haggett's novel use of quantitative statistical analysis techniques in human geographic research in 1963, these types of techniques were quickly assimilated into mainstream geographic research in Britain and America and developed into what has been termed a "revolution".
} 
offender and the effect that the construction of society had on potential offenders. Spurred on by Brantingham and Brantingham's criticism and as a result of their seminal research into the theory of environmental criminology, there was a renewed interest in the analysis of crime, but this time the main thrust addressed elements of the crime event itself, including the places and spaces at or in which crime occurs.

The 1981 publication of the Brantinghams' Environmental Criminology was seminal in that it acted as a nexus for three important theories that addressed the occurrence of crime from an explicit ecological and spatial perspective. Although environmental criminology can stand on its own as a discipline that explores patterns of criminal behaviour, especially the practice of target selection by the offender, it is actually a synthesis of knowledge in the related fields of Routine Activity Theory (Cohen and Felson, 1979), Crime Pattern Theory (Eck and Weisburd, 1995) and Rational Choice Theory (Cornish and Clarke, 1986). Research in these areas has produced complementary knowledge that environmental criminologists have used to concentrate on the role played by place and space of the crime event and the movement of offenders amongst places and through spaces. A brief description and discussion of the three major theoretical concerns with the spatial analysis of crime follows in a subsequent chapter. One of the significant findings in environmental criminology is that, like the rest of the population, offenders possess an awareness space: that space that is the set of all places about which the offender has some level of 
knowledge. This gives rise to notion of the "geometry of crime" which is a major underpinning in environmental criminology. The geometry of crime suggests that the lack of uniformity of crime is due to the lack of uniformity in offenders' awareness spaces and the lack of uniformity in the distribution of targets. The awareness space of an individual offender can be modeled, geometrically, as nodes, paths and edges that define the routine ways in which an offender exists and moves through space. A node may be a home, a workplace or a place of recreation, for example. A path would define the set of connections between these nodes for the offender. Edges determine the limits of the awareness space of a given offender based on these paths and nodes. Research has indicated that the aggregate collection of multiple offenders' awareness spaces follow a set of generalized patterns that mirror the urban form in that nodes can occur in wellknown places such as high-traffic commercial area and in that paths can generally follow high-volume transportation corridors. The following image illustrates the geometrical nature of crime as proposed by Brantingham and Brantingham. 


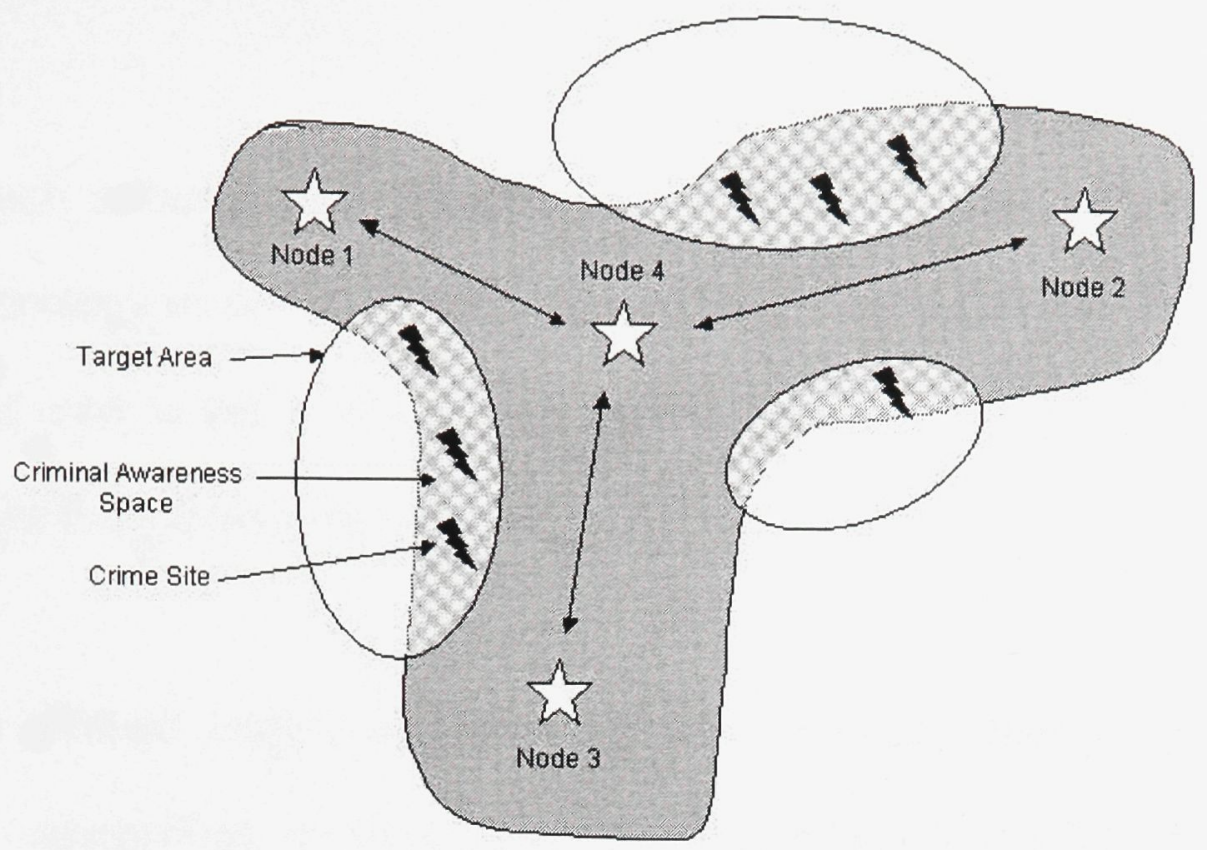

Figure 1. Geometry of Crime (after Brantingham and Brantingham, 1981). 


\section{Research Questions}

Through a thorough examination of the literature encompassing the geography and ecology of crime, through the application of a data-driven spatial prediction model and using a quasi-experimental research design, this paper seeks to answer the following questions.

1. "What major elements of the physical landscape seem to act, according to theory, as fixed spatial effects in the occurrence of residential break and enters?"

2. "What arrangement of relevant fixed spatial effects can be modeled, in conjunction with known locations of occurrences of residential break and enters, using GIS-based weights of evidence analysis to provide a useful, effective and accurate prediction of where future occurrences of residential break and enter may occur?"

This paper will discuss the nature of the theoretical bases, the methodologies employed and the observations obtained in support of the hypothesis outlined in this introduction within the scope of these two research questions. Chapter II will examine and outline the underlying theories supporting these research questions. Chapter III will describe and define Crime Potential Modelling and how the theories work with the GIS-based weights of evidence model. Chapter IV will 
provide a description and explanation of the research design approach that was taken in this thesis along with the data, systems and methodology employed in the analysis. Chapter V will discuss the results of the analysis while Chapter VI will provide conclusions and a critical assessment of the methods used in this study. 


\section{Chapter II - Theories}

\section{The Discipline of Environmental Criminology}

The research that this writer is involved with leans heavily on the evolution of thought and practice in crime mapping as well as the study of the geography and ecology of crime. Despite the wider attention (and government funding) that has arisen in recent years, the traditions of crime mapping and the ecological analysis of crime have an accumulation of over two centuries of theory and practice (Harries, 1999). The Brantinghams' 1981 analysis of "crime, maps and criminology", identified two separate waves of research into the geography of crime beginning with the adoption of the legal reforms of the Classical School which resulted in the codification of law, establishment of formal law enforcement and penal institutes (initially in Britain, and then beyond) as well as the burgeoning field of criminal justice statistics that were originally used to asses the efficiency and effectiveness of these new institutions using what is known as "utility theory". The collection of vital statistics relating to criminals and crime events provided empirical data for the so-called Chicago School of positivistic sociological thought whose theories were used as an approach to understanding crime. Since the data that were collected included spatial information, the next logical step was to organize this data spatially for comparative purposes: crime data were compared, spatially, to demographic and statistical data originating from censuses of population and other sources.

\footnotetext{
${ }^{3}$ Utility theory, as it applies to criminal justice takes a cost-benefit approach to the evaluation of implementing policies in the area of policing, law, the courts and the penal system.
} 
In the simplest terms, the practical and theoretical work that came from this period provided the basis for the fundamental belief that "crime was not homogenously distributed" across space (Brantingham and Brantingham, 1991). A large number of studies in France, Britain and the United States from subsequent decades went on to support this notion (such as: Shaw and McKay, 1942/1969; Herbert, 1975; Newman, 1980; Burgess, 1925;Cohen and Felson, 1969). These varied comparative analyses sparked research and debate into the causal relationships between demographic characteristics of geographic areas and their inherent crime constituents on scales that included national, regional, metropolitan and sub-metropolitan levels. Incidentally, developments in geographic thought were following the same parallel path: a positivist approach was being assumed in the field of human geography (Herbert, 1982). Human geographers were starting to utilize quantitative analysis at the regional or intraurban scale for pattern analysis and model building. This "Quantitative Revolution" in the spatial analysis of crime followed closely on the heels of the positivistic work being done in the field of criminology in the late 1960s. Herbert (1982) emphasizes the strong links between the geography of crime and criminology in that the geography of crime will play a "strong, descriptive role that depicts patterns in space" and how the roles of space and place can be incorporated into criminological thought and study. Herbert further stresses the important role that geographers can play in the spatial analysis of crime, particularly at the "detailed scales of street, block and individual dwelling" from which more detailed associations between space, place and crime are likely to 
emerge. Davidson (1981) recognizes both the physical location and the journeyto-crime as significant environmental elements of the crime event.

A second wave of thought developed early in the $20^{\text {th }}$ century as a direct result of the work being done in the area of social ecology by members of the Chicago School of sociology. Clifford Shaw and Henry McKay, in their original 1942 publication (and revised in 1969) examining the links between juvenile delinquency and physical, social and economic factors in spatially aggregated urban areas produced the classic studies of crime patterns in Chicago comparing delinquency rates with these other conditions. Explicit analysis of the spatial distribution of crime came from Shaw and McKay's interpretation of Ernest Burgess' 1916 theory of the concentric zone model of urban form based on the structure of urban Chicago in the early $20^{\text {th }}$ century (found in Burgess, 1925). Shaw and McKay theorized that juvenile delinquency would be most concentrated near the center of the city and would be subject to a distance decay function as one moved away from the city center. Shaw and McKay posit a form of social disorganization on top of the concentric zone model that suggests that social behaviour (economic, cultural, criminal, etc.) is driven, in part, by the urban form. They replicated this study in several other American cities using similar data and methods resulting in similar findings. Their work spawned countless other replicated studies that showed that Shaw and McKay's findings generally hold true. Brantingham and Brantingham $(1981,1991)$ are quick to point out that the research tradition and theories initiated in the $19^{\text {th }}$ century and revitalized by 
Shaw and McKay in the 1940s were being "lost in a thicket of technique". The Brantinghams point to four major logical problems (or critical concerns) that were starting to develop from the research being conducted: the confusion of the interpretation of criminal residence and crime location; the erroneous assumption of even distribution of physical, social and criminal phenomena within the spatial study units; the assumption of ecological fallacy; and, incorrect or incomplete data from official sources that could introduce bias of any sort into the analysis. These concerns contributed to the temporary demise of research interest in this field.

Finally, the Brantinghams point to the 1971 work of C.R. Jeffery's publication Crime Prevention through Environmental Design (CPTED) and Oscar Newman's 1972 work in Defensible Space as the two catalysts which triggered renewed interest in the geography and ecology of crime. In a general sense, CPTED considers physical site characteristics such as building design, landscaping and external light as potential crime prevention strategies. While Jeffrey considered the urban form, Newman examined the urban "condition" from a social perspective: he suggested that residents in an urban area have a particular, unevenly distributed stewardship over various spaces and places in any given area. The concept of defensible space is closely tied to territoriality. For example, a homeowner may have a high level of custodianship over his immediate property and, as such, may have a high level of defensibility in that immediate space. Consider then the decaying amount of custodianship that homeowner 
would have over the immediate boundary of his property and what is considered public property (i.e. a sidewalk or a street); the defensibility of that space begins to decrease. However, this simple model becomes more complex as one factor in the territoriality of multiple homeowners on the same street. The territoriality in this scenario could be enhanced in that there could be a sense of neighborhood synergy that makes that particular street more defensible that another nearby street. The opposite is true, as well: if a street of homeowners is more concerned with their immediate property and less concerned about what goes on outside their immediate boundaries, a lower level of defensibility of space is possible.

Brantingham and Brantingham also identify three shifts in perspective that set the scene for contemporary research into "crime, maps and criminology" or "environmental criminology": the shift from researchers operating with specific disciplinary bias to a criminological bias; the shift from studying the characteristics of the criminal offender to the criminal event itself; and, "the shift from the sociological to the geographical imagination" (Brantingham and Brantingham, 1991). Anselin et. al (2000) also indicate that we are experiencing a revival of the Chicago School based on the growing number of studies addressing the spatial analysis of crime that focus on the place-based theories of crime. These trends and shifts have contributed to the path of research described by the Brantinghams as: "objective analysis of the spatial and temporal variation in crime patterns in order to discover aggregate factors influencing the patterns". These "aggregate factors", in my opinion, include factors of space and place. 
The Brantinghams define crime as having four dimensions: the legal dimension, the offender dimension, the target/victim dimension and the location dimension (Brantingham and Brantingham, 1991). The "fourth dimension" of location, space or place, is the major theoretical concern in environmental criminology and certainly continues the long and storied research tradition of "crime, maps and criminology".

It is this focus on the fourth dimension of the crime event that is of immediate interest to this research. Specifically, I am interested in those physical characteristics of the landscape (natural and/or man-made) that seem to have a spatial relationship with crime events. For the purposes of my research, I have decided to focus on Residential Break and Enters (B\&Es, also known as "burglaries") as the type of crime under study. There were a number of reasons for this choice: first, one of the critical concerns of the citizens of Ottawa based on public surveys on crime and perception of crime has been residential break and enters ${ }^{4}$, second, location attributes for B\&Es are generally reliable due to insurance reporting requirements that require a police report to process the insurance claim; third, the literature surrounding the environmental criminology of B\&Es is more plentiful that other discrete types of crime (e.g. street muggings, vehicle theft, etc) from the perspective of both the crime event and the offender. Given this rationale, the thesis I am examining is the identification of a number of

\footnotetext{
${ }^{4}$ Ottawa-Carleton Regional Police Service, Environmental Scan, 1995, 1998
} 
physical features of the landscape (again, natural or man-made) that can be spatially associated with residential B\&Es for use in a predictive model.

Eck and Weisburd (1995) support the idea that the offender-centric crime theories that existed in 1995 did not adequately address the need for the study of crime events from a spatial perspective. They suggest that "Crime Pattern Theory", which joins "Routine Activity Theory" (Cohen and Felson, 1979) and "Rational Choice Theory" (Cornish and Clarke, 1986) on a nominal and spatial level to explain how certain crime targets come to the attention of offenders and how this influences the distribution of crime over space. Criminal opportunities at those places that are familiar to (potential) offenders have a higher likelihood of becoming a target - logically, there are bound to be place-based characteristics that contribute to this higher likelihood. Places with a low level of custodianship or natural surveillance (concepts embedded in the notions of defensible space and $C P T E D)$ are at greater risk for victimization. These concepts suggest that a motivated offender will weigh the risks involved in committing a crime based on his/her knowledge of the situational factors surrounding the target. Rossmo (2000) suggests that the burgeoning field of 'geographic profiling' is also built upon the intrinsic links between the three key theories of routine activity, rational choice and crime patterns. Felson (1998) points to place-based factors such as presence or absence of certain building types, zoning, mixes of land usage, absence of adults or place managers as "tangible features of local life with discernible influences on crime". This suggests that the offender uses "limited 
rationality" to assess a few of these factors in the decision to avoid or commit a crime (Felson, 1998). It stands to reason that the more familiar the offender is with the layout, security and risks involved in committing a crime at a particular place, the more rational the choice the offender could make. Wright and Logie (1988) provide empirical evidence that offenders do utilize some sort of "mental checklist" in evaluating a particular location for the commission of an offence. Their study examines a number of situational variables (residence occupied, dog in residence, locks visible, alarm installed, cover and access available for entry and escape) vs. potential attractors of crime (indications of wealth) that a potential offender would assess prior to the commission of a burglary. This notion is echoed by Rengert and Wasilchick (2000) in their examination of offender motivation and behavior vis a vis suburban burglary. The authors suggest that there are at least two choices that a potential burglar would make prior to the commission of an offence: the first is the basic decision to commit the crime and the second is the decision on how and where to commit the crime. The latter decision-making process is the area that Rengert and Wasilchick focus on; the authors propose that the "where" question is influenced by an offender's "awareness space" - that area that the offender is most familiar with through normal, legitimate or illegitimate, day-to-day routine activities.

Taylor (1998) proposes that the study of crime and place has been a progression through a spatial "cone of resolution" as we move through time. As mentioned previously, early studies of space and crime occurred at the national or regional 
level. As time progressed, these studies occurred at the community level (Davidson and Locke, 1992; Rengert, 1992; Herbert and Darwood, 1992). Currently, researchers in the field are being urged to examine crime and place at the sub-community level (Brantingham and Brantingham, 1991). Taylor suggests that there are three forces driving the study of crime and place to these lower levels of spatial resolution: efficiency and effectiveness of police in dealing with high crime areas (hotspots) rather than high-crime communities; the availability of computerized tools (GIS, for example) that aid police and criminal justice practitioners in crime analysis; theoretical models (CPTED, situational crime prevention, behavioral geography/crime pattern theory, routine activity theory, rational choice theory) that point to empirical links between crime and certain features of space below the neighborhood level (Taylor, 1998).

Clarke (1997) cites environmental criminology and its focus on the fourth dimension of place and space, along with rational choice and routine activity theory as a key factors in what he calls "situational crime prevention". Again, we see that Clarke's work focuses on the "circumstances giving rise to specific types of crime" (Clarke, 1997), most specifically, the "setting" of the crime rather than the offender. Clarke brings forward a number of studies and projects that illustrate how space can be "manipulated" to have an effect on the occurrence of crime. Newman's theory of defensible space and Jeffrey's notion of CPTED are examined in a number of meso- and micro-level scales for a variety of crime and/or disorder problems in a number of North American and British locales. 
Eck and Weisburd's 1995 text Crime and Place provides an examination of certain theories, research, practical applications and methodologies that all have place playing a central role in work being carried out. Within this text, the term "hotspot" is often referenced. The term suggests a clustering in space (and, perhaps, time) of crime events. A hotspot supposes that there is some central place around which crime occurs. Buerger et al. (1995), in Eck and Weisburd's Crime and Place, show that there are two levels of place related to hotspots: rigid boundaries of place based on property definitions and fluid boundaries of the social definition of place. Eck, with his 1998 effort with McEwen: Crime Mapping and Crime Prevention ${ }^{5}$ also delves into the notion of crime, space and opportunity.

By 1998, the burgeoning fields of crime analysis and crime mapping had infiltrated into academic institutions, professional institutes and law enforcement agencies and had taken their place as the crime prevention strategies of choice in these areas. With this infiltration came an influx of research being done by scholars and practitioners alike. That crime mapping would generate so much interest is an indication of the paramount importance being given to the notion of space and place in the analysis of crime. Implicit in this is the continuing emergence of the crime event being the main subject of research interest. By 1998, there was a significant body of knowledge in crime pattern theory from

\footnotetext{
${ }^{5}$ This is Volume 8 in the Crime Prevention Studies series published by the Criminal Justice Press. Eck and Weisburd's 1995 Crime and Place was Volume 5 in the series.
} 
which to perform practical, theory-based spatial crime analysis. This trend continues on into the present day.

An initial scan of this growing body of knowledge examining the interplays between crime and place indicates that there are numerous qualitative and quantitative studies that investigate and support the notion of spatial links between physical features and crime that gives the supposition of place having a role in the occurrence of crime much merit (Shaw and McKay, 1942/1969; Rengert and Wasilchick, 2000; White, 1990; Beavon et. Al, 1994, Hesseling, 1992; Robinson, in progress). Generally speaking, these characteristics and associations include: proximity of crime events to natural and/or man-made features (i.e. adjacency to vacant land use, distance from schools); concurrent placement with certain features (i.e. residential B\&Es will only occur within residential land uses). Robinson's hypothesis is that the unique nature of distinct combinations of each type of land use and their associations with crime have a natural level of interplay that can create differential levels of opportunity when combined. Naturally, there will be no one measure of proximity or adjacency that will determine the level of spatial association of these crime events with any given physical feature, so a metric must be devised to ascertain the proximal threshold that a physical feature will have on a particular crime event. This metric can then be used as a predictive tool, as in: "it is more likely that a vehicle will be stolen at or near a parking lot than anywhere else". In order to realize the definition of these measures of likelihood and proximity, it is necessary to identify 
and isolate the most important physical features that could play a role in the most meaningful and reliable measurements of likelihood and proximity. I am calling the physical features of the landscape that could be effectively used in this role "fixed spatial effects". 


\section{Three Key Theories Supporting Crime Potential Modelling}

This thesis will specifically address the first research question's implication that theory can be used to support the notion of fixed spatial effects in the prediction of residential break and enters. In the research outline, three key theories were identified as being central to the role of space and place in crime, specifically, how offenders utilize space and place in the decisions that they make in committing crimes. These theories were: Crime Pattern Theory (Eck and Weisburd, 1995), Routine Activity Theory (Cohen and Felson, 1979) and Rational Choice Theory (Cornish and Clarke, 1986). Aligned with the schools of thought implicated in these theories is the work of Brantingham and Brantingham (1981, 1991 ) in their research into "environmental criminology", a burgeoning field in both criminological thought and in the world of policing. The Brantinghams define Environmental Criminology as the "study of the interaction between people and what surrounds them" (Brantingham and Brantingham, 1998). Curiously, this sounds like one of the definitions of human ecology: the interaction of the human culture and the environment, albeit environmental criminology focuses on the activities that dictate where and when criminal opportunities are created through this culture/environment interaction.

A brief note must be made here around the notion of "fixed spatial effects". Email communications between myself and Dr. Will Gorr (Professor of Public Policy and Management Information Systems at the Heinz School at Carnegie-Mellon 
University and noted expert on the predictive modeling of crime, amongst other things) on the subject of predictive modeling has led me to reconsider the notion of "fixed spatial effects" as it applies to the influence that land use could have on an individual intent on committing a crime. I had identified, through a comprehensive Literature Review (December 2, 2002), the following land uses that seemed influential in where residential break and enters were likely to occur:

1. Proximity to commercial land use - based on Shaw and McKay (1942)

2. Proximity to vacant land use and parkland - based on Shaw and McKay (1942) and Rengert and Wasilchick (2000)

3. Proximity to main thoroughfares - based on White (1990) and Beavon et al. (1994)

4. Proximity to 4-node intersections - based on Beavon et al. (1994)

5. Proximity to pedestrian thoroughfares (urban trails) - based on Beavon et al. (1994)

6. Land use type by housing density class - based on Hesseling (1992)

Dr. Gorr suggested that these elements would be considered fixed effects in any sort of quantitative predictive model while the actual known occurrences of recent residential break and enters would be considered leading indicators. This paper will take and carry forward Dr. Gorr's recommendations on nomenclature in order to be consistent with the terminology in use in the world of predictive modeling hence the notion of "fixed spatial indicators". As will be discussed in subsequent 
chapters, the Weights-of-Evidence model considers leading indicators to be "training data" for the model, so it is not necessary to carry the term "leading spatial indicators" any further in this report.

Notwithstanding the change in terminology, this paper will examine the theoretical bases that each of these fixed effects employs in supporting the idea that these land uses can be employed as variables in the GIS-based weights-ofevidence predictive model in order to calculate the probability of where future residential break and enters are more likely to occur given where they have occurred in the recent past in conjunction with the various land uses identified above as "fixed spatial effects".

Before getting into a discussion around the specifics of each of the three key theories being examined (Crime Pattern Theory, Routine Activity Theory, Rational Choice Theory), it is important to back up our thoughts and scrutinize the commonalities of these theories. Each of these theories presupposes that opportunity is treated as the "true generator of crime" (Police Foundation, 2003). Event-based criminology (as opposed to offender-centric criminology) relies on the "Crime Triangle" (Cohen and Felson, 1979) to explain the opportunity structure of crime: opportunity is created where a motivated offender and a suitable target come together at the same place at the same time. 


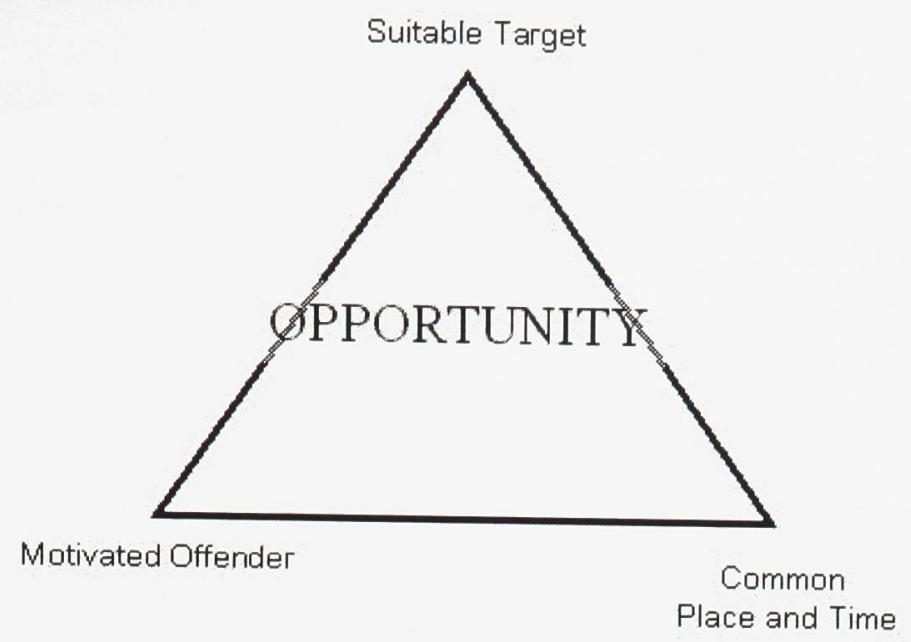

Figure 2 Crime Triangle (after Cohen and Felson, 1979)

A crime event can only occur when an opportunity is created and Felson and Clarke (1998) argue that space and place characteristics play a central role in how a motivated offender makes his or her decisions on where to seek out criminal opportunities. Felson and Clarke also present in their work on crime prevention the "Ten Principles of Crime Opportunity" (1998) that purposely avoid the lengthy list of criminology theories that address offenders' motivation and instead address the identification and minimization of the various opportunities that exist for offenders. The following list summarizes a few specific principles that apply to the research that I am conducting:

- Crime Opportunities are highly specific

- Crime Opportunities are concentrated in time and space

- Crime Opportunities depend on everyday activities of people 
It is also worthwhile to identify that the key differences between the three theories are in the scope and scale of their spheres of influence: Routine Activity Theory takes the "society as a whole" perspective, while Crime Pattern Theory situates itself within the characteristics of a local area, and Rational Choice Theory addresses the behaviour of individuals based on their knowledge of the surrounding environment. 


\section{Rational Choice Theory}

Cornish and Clarke (1986) argue that target selection by a motivated offender is dictated by rational decision-making behaviour on the part of the criminal based on the surrounding social and physical environment. The would-be offender process factors such as risk and reward as well as specific situational factors related to the target. Rengert and Wasilchick (2000) provide a number of rational site selection indicators that a burglar would use in determining the suitability of a particular residence as a break and enter target: proximity to neighbouring houses, property layout, proximity to open or unused land, proximity to land that generates pedestrian traffic and proximity to major thoroughfares. While these decisions can be made for a variety of reasons (cover, access, escape, concealment, anonymity), it remains that the physical structure of space provides important decision-making cues for a motivated offender to evaluate suitable targets. Seemingly, risk analysis is a significant element of rational choice but not all offenders practice rational choice in a uniform manner.

Lersch (2004) gives the example of an event decision process specific to residential break and enters: "Once the decision has been made to commit a residential burglary, the offender must select a specific target. A neighborhood must be selected that offers the lowest level of (perceived) risk, and within this neighborhood the burglar must choose which home will be attacked". Lersch goes on to say that these choices will be based upon the burglar's assessment of 
opportunity, required effort, risks and rewards. Sometimes these decisions are made quite carefully and sometimes they are made quickly (Cornish and Clarke, 1986; Rengert and Wasilchick, 2000; Lersch, 2004), however the argument of rational decision-making still applies. 


\section{Crime Pattern Theory}

Drilling down by one level of scope and scale, Crime Pattern Theory addresses the crime problem from a localized perspective as opposed to the global, societal perspective. First brought to light in 1995 by Eck and Weisburd in their coauthored introduction to Volume 5 of the Crime Prevention Studies series entitled "Crime and Place" (Police Executive Research Forum, 1995), Crime Pattern Theory expands on the notion that the occurrence of crime is more likely in those areas where offenders' criminal awareness space and target-rich areas intersect. Brantingham and Brantingham first proposed this notion in their "notes on the geometry of crime" in their original text Environmental Criminology (1981) and sought to describe how people (and offenders) tend to move routinely throughout space and apply some sort of geometrical construct to it. Cohen and Felson (1998) also review the notion of the geometry of crime. Crime Pattern Theory invokes three constructs of space that should be familiar to the geographer or anyone with a geomatics background:

- Nodes - core basis for an awareness space; a node would account for those places that an offender would consider an anchor point - a home, workplace, school, place of recreation or entertainment that would be considered a place where an offender spends a good deal of time. Nodes would tend to be distributed throughout an urban environment in a somewhat clustered manner. Nodes can be further defined as those 
places to which offenders travel to and from in the course of their daily activities, so Routine Activity Theory presents itself here once again.

- Paths - the routes by which the offender travels to and from any and all nodes. Generally, and most frequently, these paths will tend to be routes that are also used frequently by the general population and will tend to represent principal transportation corridors. Of course, intimate local knowledge of discrete pockets of the landscape is entirely possible, but these represent a small proportion of an offender's network of paths. As well, paths are subject to change over time as the physical location of nodes change with normal life changes (change in residence, change in school, change in work, change in relationships, change in lifestyle, change in tastes, etc.).

- Edges - represent the boundaries of those areas that are for all intents and purposes defined by the locations of an offender's nodes and the paths that they take traveling to and from any and all nodes. Edges represent the bounding polygon that serves to illustrate an offender's criminal awareness space.

See Figure 1 on p.7 for an illustration of node, paths and edges and how they relate in space. 
Crime Pattern Theory is important in that it combines the theories behind routine activity and rational choice in explaining the distribution of crime events in space. Looking back to the Crime Triangle, the uneven distribution of offenders, targets, handlers, place managers and guardians serves to present differential opportunities in different places at different times and will, to a large degree, explain the distribution of crime events and describe crime patterns (Eck and Weisburd, 1995). Invoking the notion of human ecology again, Eck and Weisburd suggest that Crime Pattern Theory seeks to explore and explain the interaction between offenders and their physical (as well as social) environment. Brantingham and Brantingham's train of thought has to do with how and where suitable targets come to the attention of motivated offenders through their occupation in routine activities.

Bringing the ideas behind Crime Pattern Theory back to the fixed spatial effects that I am using in my research, it is quite easy to see the link between each and every one of these effects and the choices that were made to include them in the crime potential modeling. If the patterns of nodes, paths and edges were laid out for many people, including many offenders, a pattern would emerge that mirrors the urban form: offenders' residence would be found in areas where residences are a major land use; offenders' paths would tend to follow major thoroughfares and offenders' edges, thus awareness spaces, would mirror those of the rest of society with similar anchor points. The main difference is that when you overlay 
target rich areas, an offender's awareness space then becomes criminal awareness space that is narrowed considerably.

Rengert and Wasilchik (2000), Shaw and McKay (1942), Beavon et al. (1984) and White (1990) all provide concrete examples of how Crime Pattern Theory informs their research, despite the fact that the term "Crime Pattern Theory" did not come into use until the Brantinghams started working in the field of environmental criminology. Shaw and McKay referred back to E.W. Burgess' concentric zone theory of the urban form in Chicago in the early part of the $20^{\text {th }}$ century to inform their theory on social disorganization. Shaw and McKay found correlations between juvenile delinquency and commercial/industrial land use in their seminal studies. I have extrapolated this relationship on the basis of this work and later works by Rengert and Wasilchick and Eck and Weisburd about the arrangement of space and the occurrence of crime.. In Ottawa, it could be easily demonstrated that there is a high degree of correlation between commercial and industrial land use and the proximity of major transportation thoroughfares. 


\section{Routine Activity Theory}

Brought forth by Cohen and Felson in their 1979 journal article Social Change and Crime Rate Trends: A Routine Activity Approach, Routine Activity Theory focuses on the characteristics of the crime rather than on the characteristics of the offender. Cohen and Felson argue that, given a constant supply of motivation for offenders to commit crime, the supply of motivated offenders will remain constant. They also argue that in order for a crime to occur, there must be opportunity (requiring a motivated offender, a suitable target and a common time and place) as it is defined within the context of the Crime Triangle. However, they take the Crime Triangle one step further and suggest that opportunity is enhanced given the absence of:

- handlers that monitor potential offenders (parents, parole officers, etc)

- place managers that monitor specific spaces and places (homeowners, etc), and

- capable guardians that monitor specific targets (store security guards, police, etc.)

Cohen and Felson suggest that the routine activities of offenders (legal or illegal activities) in their work, play and leisure affect the convergence of their activities and the activities of other people/targets engaged in legal activities. The basis of this argument is their examination of long-term crime rate trends in the U.S. 
between 1960 and 1980. They state that the increase in residential property crime was a result of the change in the social dynamics in this period. With more people, women specifically, leaving the home during the day to work, this left many residences without a place manager to monitor their property and prevent crime. Expand this to many residences, many neighborhoods and many cities and the notion of the absence of place managers can be aggregated to indicate a societal change that had an effect on the occurrence of crime; the occurrence of crime is related to the nature of everyday social interactions in particular spaces and places. Their work gave rise to what is called "situational crime prevention" which identifies those activities within a place or those characteristics of a place that would serve to prevent crime in that place. Marcus Felson, in his text Crime and Everyday Life (1998), looks to the modus operandi of the offender in residential break and enters (aka "burglary" in American publications) in providing support for his "ingenuity fallacy": burglars that he interviewed showed that they employed an almost casual approach to committing burglaries, usually taking the quick and easy approach, definitely unplanned, yet still employing some sort of analytical process that measures the relative risks and rewards of any potential target. When applying this theory, and this way of thinking, to the fixed spatial effects that are central to this research project, the burglar would choose a street that would provide easy and familiar access to suitable targets, provide easy and familiar escape from the neighborhood and that would provide adequate payoff based on their knowledge or perception of the potential rewards contained in a particular residence. For a motivated offender to make these decisions, he or she 
must have some sort of prior knowledge - what Brantingham and Brantingham call offender "awareness space" and "activity space" (1981). An offender's awareness space is dictated by how and where they move through their environment and how familiar they are with this environment and this is built upon the Brantingham's construct of the geometry of crime - specifically the sets of nodes, paths and edges that an offender possesses and uses in routine, legitimate activities as well as their criminal activities. How this happens is arguably defined by what an offender does when they are not busy committing crimes and how they move about.

Another dimension is the specific locations of the targets relative to the activities and movements of an offender. Routine Activity Theory takes all of this into account as well as aggregates the awareness spaces and activity spaces of multiple offenders and multiple targets in order to define some sort of dispersion of risk. Rengert and Wasilchick (2000) argue that homes located closer to parkland or vacant land have a greater risk of being burglarized due to the easy approach and escape to and from the target without detection or arousing suspicion because of a higher probability of legitimate pedestrian traffic close to the home. When considered from a routine activity approach, an offender's awareness space is considerably increased in those areas where he or she may not be a resident by having easy access in around the periphery of a residential neighborhood. As well, a neighbourhood could become a part of an offenders'

\footnotetext{
${ }^{6}$ Rengert and Wasilchick (2002) define (criminal) activity space as the subset of that awareness space will function as a "search space" for criminal opportunities. See p. 40-41 of this report for further discussion.
} 
criminal activity space if that offender enters that neighborhood on legitimate business. Rengert and Wasilchick (2000) document the case where a burglar was employed as a roofing labourer on a residential construction site. This individual's vantage point on a roof gave him the perfect opportunity to survey the neighborhood in order to increase his supply of potential targets. Likewise, the routes that this individual took to arrive and leave the job site allowed for the expansion of his criminal awareness space. In a similar fashion, Shaw and McKay propose the same dynamic for commercial and/or industrial land use. The routine activities of a legitimate user of this type of space allow for offenders to blend into the environment better than in one that is homogenously residential where it could be more obvious that they are engaged in illegitimate activities.

The studies done by White (1990), Beavon et al. (1994) and Rengert and Wasilchick (2000) speak to the effect that the physical layout of residential areas and their proximity to other land uses has on the level of opportunity that exists in any particular neighbourhood. White and Rengert and Wasilchick both explore the idea of proximity of a residence to a major thoroughfare or highway off-ramp as providing a better opportunity for a break and enter to happen as opposed to residences located further away. Again, these studies invoke the Routine Activity Theory as well as imply the idea of the criminal awareness space in that the closer a residence is located to a major thoroughfare, it is more likely to fall into the awareness space of people with legitimate behaviours as well as being more likely to fall into the criminal awareness space of a motivated offender. In his 
study on "neighborhood permeability" and residential burglaries, White was able to correlate rates of residential B\&Es to the counts of certain types of access points in aggregated blocks of residential land use. White bases his theory on Taylor and Gottfredson's (1986) concept of permeability that is concerned with the degree to which outside traffic can pass into a given residential area. Traffic volume within neighborhoods is also a factor. White defines permeability of neighborhoods by the number of access points from main traffic arteries into a neighborhood. Permeability, according to White, has a doubled impact: the more routes into a neighborhood, the greater the chance that any target within that neighborhood may be selected and the greater the opportunity to escape is afforded. Evidently, Rational Choice and Crime Pattern Theories are invoked in White's study. White was able to prove that permeability had a significant influence on burglary rates after other economic and social factors were controlled for.

Beavon, Brantingham and Brantingham (1994) go one step further into the neighborhood - right down to the street level, in fact, in their study of the influence of street networks on the patterns of B\&Es. The authors draw on the 1977 work of Bevis and Nutter who found that burglars prefer to work in areas that are familiar and that provide targets that are convenient to access and escape from. The notion of permeability is extended in this study to look at the access level of each individual street segment and determine the relationships that exist between the various structures and the rates of B\&Es. Drawing on 
Bevis and Nutter's typology of street types, Beavon, Brantingham and Brantingham were able to identify that lower residential burglary rates were associated with streets having low accessibility. They defined street accessibility based on the number of turnings from adjacent intersections into each street. Therefore, a street could have as few as one turning into it (i.e. cul de sac), as many as four turnings (single cross street intersection) to as many as 6 turnings (cross street intersection at each end of the segment). As well, they looked at the traffic volume on each street segment based on whether they were a highway, major or minor artery or a feeder street. They discovered a direct linear relationship between the number of turns and rates of B\&Es as well as a direct linear relationship between the volume of traffic and rates of B\&Es, at the street level. They were also able to identify that pedestrian pathways brought greater volumes of property offences to the areas in which they exist. Seemingly, Routine Activity Theory figures significantly into the results observed in both of these studies in that the familiarity and the accessibility of a given space provides an elevated level of opportunity for an offender to access a target as well as enough "cover" to make escape easier.

A Dutch study examined the neighborhood-level analysis of relationships between housing type and occurrence of crime and offender mobility (Hesseling, 1992). Hesseling shows that there is a positive relationship between housing types (based on density, single unit dwellings vs. multiple unit dwellings) and this notion of offender mobility. This relationship indicates that a neighborhood with 
lower housing densities provides a better opportunity structure for the offender. I read this as being implicated into the Routine Activity Theory approach in that the routine activities of offenders and non-offenders alike are somewhat determined by the physical construct of the local environment. If housing density were high in a given area, natural surveillance and the notion of defensible space within these areas would be high and would present a correspondingly higher risk to the motivated offender thus creating a much lower opportunity structure. Houses that are spread out farther arguably have less potential for natural surveillance and a lower degree of defensible space and a correspondingly greater degree of opportunity for a motivated offender. Of course, these relationships are far from being this simplistic and linear, but that is what modeling the actual occurrence of residential B\&Es can attempt to quantify, to some degree. 


\section{Chapter III - Crime Potential Modelling}

\section{The Ecology and Spatial Prediction of Crime}

The three complementary theories of environmental criminology (Routine Activity Theory, Rational Choice Theory and Crime Pattern Theory) suggest that land use is an important consideration in the potential of where crime may occur. A number of major studies embody the land use hypothesis that infers that social activity related to a variety of land use types has quantitative links to crime, disorder and delinquency (Burgess, 1925; White, 1932; Shaw and McKay, 1942; Harries, 1980; Brantingham and Brantingham, 1991; Felson, 1997). The categorical type of land use is important, but so is the construction of certain types of land use, specifically transportation networks. The concept of permeability of space is a major theme in a number of crime event studies (Beavon, Brantingham and Brantingham, 1984; White, 1990): it is argued that the arrangement of street networks plays a role in the offender's use of space (awareness space) and thus in the activity of target selection on the part of the offender.

Rengert and Wasilchick (2002) take the geometry of crime one step further in the deconstruction of an offender's awareness space. The authors propose that, out of the set of awareness space that an offender possess, a subset of that awareness space will function as a "search space" for criminal opportunities. Furthermore, "criminal activity space" is a subset of the offender's "search 
space"; once a suitable a target has been found, it can then be acted upon in a criminal manner if favourable conditions exist at the discretion of the offender. So, the criminal activity space is the space that is overlapped by the offender's awareness space and the space occupied by suitable targets. In theory, it is in these spaces, when occupying the same space at the same time, that there is a greater potential for crime to occur. Since it is possible to model these types of areas spatially, based on the relevant theories and existing spatial information in the form of land use databases, I believe that this type of model can be used in a predictive fashion to isolate those areas that have a greater potential for the occurrence of future crime events, specifically when performed in a GIS environment using the weights-of-evidence model. 


\section{Fixed Spatial Effects}

In studying the literature of the ecology and geography of crime, it becomes quickly apparent that researchers such as Shaw and McKay, R.C. White, Felson, Rengert, the Brantinghams and a host of others felt that it was important to conduct qualitative and quantitative research on the links between human ecology and crime. From the seminal social disorganization studies of the 1920 s and 1930s in Chicago to the research into environmental criminology in the 1970s and 1980s, an obvious pattern exists that links, in varying ways and to varying degrees, crime and criminal activity to the uneven spatial distribution of socio-economic factors such as wealth, ethnicity, education and the uneven spatial distribution of natural and manufactured physical features such as land use and public services. It is from the literature in this particular intersection of criminology, sociology and ecology that I will attempt to draw out a number of important physical features that may play a role in the influencing the uneven spatial distribution of residential break and enters (B\&Es) in the central core of the city of Ottawa.

This takes the concept of a "fixed effect" of crime to the spatial level. Rather than simply ask what factors are specific precipitators of crime, a fixed spatial effect asks to what degree are certain spatially distributed physical features related to the occurrence of B\&Es? For example, a "non-spatial" fixed effects of crime could be wealth - as in, lack of wealth could be highly correlated to the propensity to 
commit crime at the individual level. Although this example is quite generalized, there are certainly many more specific examples in the behavioural criminology literature. A fixed spatial effect would take into account the coincidence of specific crimes and relationship that these crimes may have with many individual socio-economic and/or physical features of a landscape. A thorough scan of the literature in the ecology and geography of crime is rife with fixed spatial effects. For example, Shaw and McKay correlated the distance to Chicago's urban commercial core to juvenile delinquency. They found that the closer a neighborhood was situated to the urban core, the greater the rate of juvenile delinquency (Shaw and McKay, 1942/1969). Not only did they see this pattern in Chicago of the 1920s, but also in Boston and Philadelphia in the same era. The degree of the relationships between crime and distance to urban core differed for each of the cities, but the overall pattern was consistent. The fixed spatial effect in these studies would have been the proximity of any discrete area to the central urban core. Another factor that was an important finding of Shaw and McKay was the proximity of neighborhoods to commercial land uses. Again, the closer a neighborhood was to commercial land use, the greater the rate of delinquency. Although these studies observed the rates of delinquency (as in "where the delinquents were located"), it follows that, based on the Brantingham's model of the occurrence of crime, where delinquents are, it is possible for crime to occur. This study launched a multitude of similarly constructed quantitative studies that examined the patterns of crime and the uneven spatial distribution of many different features. 
Another set of particularly interesting studies looked at neighborhood structure in the areas of housing density (Hesseling, 1992) and neighborhood permeability (White, 1990). Hesseling looked at, among other factors, property crime rates as they were related to housing density - density proves to be a compelling leading indicator based on the fact that high density housing provides more opportunities per unit area than does low density housing (Hesseling, 1990). It follows that if the opportunity rate is high, then the occurrence rate could be high if the targets are suitable and the offenders are present. Hesseling cites works by Repetto (1974) and Sampson (1993) that found that crime rates are higher in areas with greater housing density. As such, we have determined another fixed spatial effect in the form of levels of housing density. Assuming the existence of suitable targets, Hesseling also shows that offenders are willing to travel (within cities) to areas where opportunity is greater (offender mobility) so that the offender doesn't actually have to reside in an area with suitable opportunity and suitable targets.

Neighborhood permeability looks at how easily space is accessed from the outside by outsiders. Garland White's (1990) and Beavon's (1994) studies on neighborhood permeability, street structure and property crime rates provided significant context for this paper. The key factors that these researchers uncover in relationship to permeability are: i. how close a neighborhood is to a major thoroughfare (how easy it is to access that neighbourhood,) and ii. how street structure influences travel once inside a neighborhood (how easy it is to travel 
within that neighborhood). Proximity to major thoroughfares comes into play in how an offender (generally) manipulates his space - the more familiar an offender is with an area, the more likely he could be led to offend in that area. Although this generalization is simple, the concept of routine activity and offender use of space is well documented by Felson (1998) and Rengert and Wasilchick (2000). Thus, we uncover another fixed spatial effect.

The 1994 work of Beavon, Brantingham and Brantingham also looks to the influence of street pattern on property offences. The internal street structure of a neighborhood is more intriguing in that the offender's choice of a path through a neighborhood is likely influenced by perceived opportunities and perceived risks while scouting targets and these factors are quickly and subjectively balanced by the offender (Beavon, Brantingham and Brantingham, 1994; Rengert and Wasilchick, 2000). Given the offender's need to balance risk and opportunity, Beavon uncovers a relationship between the accessibility of a neighborhood and the rate of crime in that neighborhood. The greater the number of turns at intersections, the more likely crime is to occur. Again, this concept can be used as another fixed spatial effect. Beavon, Brantingham and Brantingham also look at the inclusion of pedestrian thoroughfares in assessing accessibility of spaces for the purposes of committing property crime, a factor that is supported by Rengert and Wasilchick (2000). Yet another fixed spatial effect is uncovered here. 


\section{Weights-of-Evidence (WofE) and Crime Potential Modelling (CPM)}

It is the desire of this researcher to integrate the knowledge that has been gained in the area of ecology of crime and, specifically, environmental criminology in order to provide a better understanding of the aggregate interaction of a number of fixed spatial effects and the locations of occurrence of residential break and enters in the urban area. The GIS-based weights-of-evidence model is a datadriven, predictive, raster-based, multiple map modeling technique that uses Bayesian conditional probability theory to generate a "posterior probability map". Current trends in the spatial analysis of crime indicate that research being conducted in the area of knowledge-driven prescriptive models such as "hot spot" and "hot place" modelling (Block and Block, 1995), fuzzy logic, neural networks and artificial intelligence methods (Anselin et al., 2002; Gorr and Olligschlaeger, 2000). There has been no academic or applied research publication of any type that has indicated the use of the GIS-based weights-of-evidence in the spatial analysis of crime, aside from what has been done by this researcher to date. In fact, GIS-based weights-of-evidence has been almost exclusively used in the domain of mineral exploration by geologists with the Geologic Survey of Canada and the U.S. Geological Survey (Bonham-Carter, 1994). Bonham-Carter, in the user guide for the ArcWofe and Arc-SDM (Arc Spatial Data Modeller) software (Kemp et al.) implicitly indicates uses of WofE modelling of seismic data and other geologic features. This suggests that WofE modelling could be used outside of the realm that it was intended for. 


\section{Spatial Prediction Models - the Weights-of-Evidence Model}

Bonham-Carter (1994), in his all-encompassing volume on spatial analysis in GIS has identified a number of methods of measuring, comparing and contrasting the spatial differentiation of spatially referenced information within a GIS. For the purposes of the remainder of this paper, I will refer to discrete pieces of spatially referenced information as "layers", as does Bonham-Carter. These methods range from simple single map analysis that looks at the relationships that exist in a single layer (think "proximity" of one entity to another) to methods that employ sophisticated multiple map/mathematical modeling in fuzzy logic, neural networks and artificial intelligence. Each of these modeling techniques, when used in a GIS, has the ability to be populated with map layers as input variables. The operations that are carried out on them can be quite complex, but the ultimate output of any of these is some sort of map. The following is an illustration of the concept of multiple map modelling.
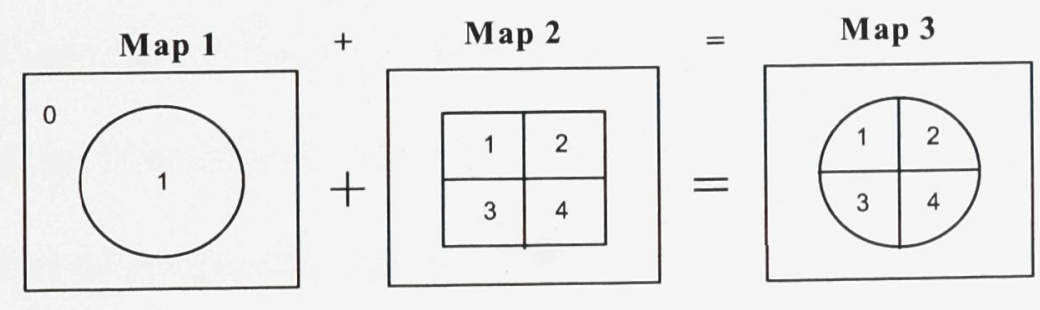

After Bonham-Carter (1994)

Figure 3 Map Algebra 
Of course, this is a simple example as other mathematical operators and functions can be used in all sorts of ways. Essentially, though, an output map is a function of some input maps operated on by some mathematical process. This is called "map algebra". The strength of GIS in these operations is its particular ability to combine disparate spatial datasets for the purposes of analysis and prediction (Bonham-Carter, 1994). From the simple example illustrated above, it is obvious that a map, representing one layer, can have more than one class per layer. Think of a map layer representing soil cover in a given area - within the area, it is possible that there is more than one soil type - these different soil types are different classes within the soil layer in the given study area. Taking it one step further, say that within the same study area, there is a forest cover layer and this layer represents several different tree species. The tree species represent different classes within the forest cover layers. Consider now if a map overlay analysis was performed on the soil layer and the forest cover layer to examine the patterns of coincidence of various soil types and species types. It is apparent that we can determine that certain soil types can favor certain tree species. Even in this simple example, the power of multiple map analysis is evident. Weights-of-evidence, while not as esoteric a model as fuzzy logic, neural networks or artificial intelligence when it comes to predictive mapping, spans the gap between these and the simple model illustrated in the map overlay analysis above and it is no less powerful than any of them. 
Weights-of-Evidence (WofE) modeling originated from a number of different disciplines ranging from quantitative medical diagnosis for disease prediction, to ecological modeling and to mineral exploration for mineral deposit prediction (Bonham-Carter, 1994). Bonham-Carter exploited the predictive nature of weights-of-evidence modeling and applied a spatial component to it through the use of GIS starting with his mineral potential mapping tool called Prospector.

WofE modeling is a data-driven predictive model (Bonham-Carter, 1994) that differs from other predictive map models that are either knowledge driven and/or prescriptive in nature. The distinction between a data-driven model and a knowledge-driven model is apparent in that the WofE model relies on objective assessment of input data to "estimate the relative importance of evidence by statistical means" (Bonham-Carter, 1994, p. 301). Rather than employing knowledge driven subjectivity in populating other similar map models, WofE uses the training data layer to make suitable adjustments to the mechanics of the model itself. The ultimate goal of this form of map modeling is to predict the likelihood of the occurrence of a particular phenomenon (whether it be in other places and/or times) within a certain study area based on one or more layers of evidence. WofE modeling employs a log-linear form of the Bayesian conditional probability function that requires evidence in the form of discrete map layers and training data to prime the model. 
Conditional probability is a form of probability developed by the mathematician Bayes in the $18^{\text {th }}$ century that assesses the probability of a phenomenon occurring based on the presence or absence of another phenomenon. Within the confines of this paper, we are assessing the probability of a residential break and enter occurring based on the presence or absence of a fixed spatial effect. The following diagram illustrates the spatial overlap relationships between a map pattern (layer of evidence) and the deposit pattern (training data). The terms "pattern" and "deposit" are terminology drawn directly from Bonham-Carter's work.

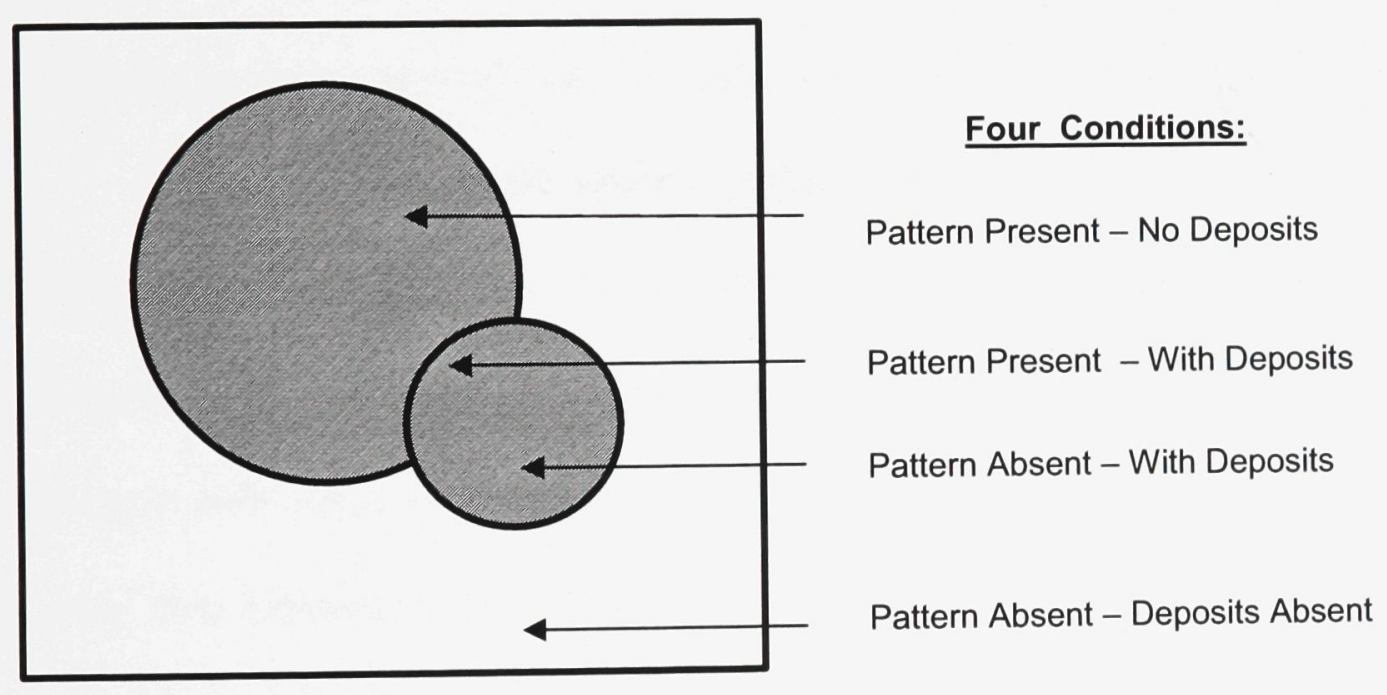

After Bonham-Carter, 1994

\section{Figure 4 - Venn diagram of Conditional Probabilities}

The WofE model starts with what is called prior probability - the raw probability of a deposit occurring within a study area based on the ratio of area of deposits to the total study area. The WofE model then builds in the conditional probability of 
each of the layers of evidence and then assesses these layers as to their individual class weights using log-linear manipulation, in conjunction with the training data layer, to produce a final output map called a posterior probability map. In our example of soil type/tree species overlay analysis, we can expand that to predict, say, the occurrence of a particular pest or parasite (the "deposit") over the entire study area by what we know from a smaller sampling of known occurrences and the existence or absence of particular soil types and tree species types (the "patterns"). We can determine the prior probability of pest occurrence based on the ratio of area of occurrence to total study area. If, for example, our study area is 10,000 square units and the occurrence of pests covers (contiguously or not) 1000 square units, the prior probability would be:

\section{0 units / 10000 units $=0.1$}

or $10 \%$ probability. Now, say, for example, we want to concentrate on whether the "sandy loam" soil type and the "Douglas fir" tree species type is located in conjunction with each other and the occurrence of some sort of pest. This brings into play two instances of conditional probability that assess the presence or absence of the pattern and the presence or absence of each type of deposit (soil or tree). These conditional probabilities generate what are called "likelihood ratios" that exist for each unique condition. Given that there are now two layers of evidence in the mix, we now have more than the four simple conditions based on one pattern and one deposit. We have two patterns (soil and tree species) and the single deposit (pest). We now need to understand the likelihood of pest occurrence given each combination and permutation of layers. Likelihood ratios 
are used to determine the various measures of probabilities based on each unique condition. Given a single layer of evidence, a likelihood ratio called a "sufficiency ratio" is a function of the probability of a pattern and a deposit being present divided by the probability of a pattern being present and the deposit being absent. A similar action is taken to determine the "necessity ratio", namely, the function of the probability of a pattern being absent while a deposit is present divided by the probability of neither a pattern nor deposit being present. The following paragraph illustrates the procedures that were followed in the WofE modelling process using a simple example from an earlier exploratory spatial data analysis (ESDA) stage of this project.

\section{> Calculation of Prior Probability}

- Is the probability that a unit cell in the study area, chosen at random, contains a known occurrence.

- Calculated using the average density of , or count of cells containing, known deposits within the bounds of the study area

For example, 212 B\&Es covering 212 cells in our study area of 945 (10 mx10m),

Prior Probability, $\mathrm{P}\{\mathrm{T}\}=212 / 945$

$$
=0.2243
$$

or, there is a $\mathbf{2 2 . 4 3} \%$ probability that any given cell in our study area, chosen at random, will contain a $B \& E$ occurrence based on the observed pattern of training points 


\section{Calculation of Conditional Probabilities}

Based on the Bayesian probability functions (4 cases):

\begin{tabular}{|c|c|c|c|}
\hline & \multicolumn{2}{|c|}{ Training Data } \\
\hline \multirow{3}{*}{ 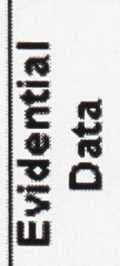 } & & Present & Absent \\
\hline & Present & $P\{E \mid T\}$ & $P\{E \mid \mp\}$ \\
\hline & Absent & $\mathrm{P}\{\overline{\mathrm{E}} \mid \mathrm{T}\}$ & $P\{\bar{E} \mid \mp\}$ \\
\hline
\end{tabular}

\section{Calculation of Conditional Probabilities for a Binary Layer of Evidence}

Case 1: $P\{E \mid T\}=P\{E \cap T\} / P\{T\}$

- probability of evidence $(E)$ being present, given the presence of an occurrence $(T)$

Case 2: $P\{E \mid \mp\}=P\{E \cap \mp\} / P\{\mp\}$

- probability of evidence $(E)$ being present, given the absenœe of an occurrence $(F)$

Case 3: $\mathrm{P}\{\overline{\mathrm{E}} \mid \mathrm{T}\}=\mathrm{P}\{\overline{\mathrm{E}} \cap \mathrm{T}\} / \mathrm{P}\{\mathrm{T}\}$

- probability of evidence $(\bar{E})$ being absent, given the presenœe of an occurrence $(T)$

Case 4: $P\{\bar{E} \mid \mp\}=P\{\bar{E} \cap \mp\} / P\{\mp\}$

- probability of evidence $(\bar{E})$ being absent, given the absence of an occurrenœe $(\mp)$ 


\section{Calculation of Evidential Theme Weights for a Binary Layer of Evidence}

$W+$ and $W$ - are based on 'likelihood ratios' calculated from the Bayesian probabilities.

D W Wakes the natural logarithm of the 'Sufficiency Ratio' (LS): the ratio of Case1 to Case2

$$
\begin{aligned}
W+ & =\log _{e} L S \\
& =\log _{e}(P\{E \mid T\} / P\{E \mid \mp\}) \\
& =\log _{e}((13 / 212) /(11 / 731)) \\
& =1.4573
\end{aligned}
$$

> W- takes the natural logarithm of the 'Necessity Ratio' (LN): the ratio of Case3 to Case4

$$
\begin{aligned}
\mathbf{W}- & =\log _{\mathrm{e}} \mathrm{LN} \\
& =\log _{\mathrm{e}}(\mathrm{P}\{\overline{\mathrm{E}} \mid \mathrm{T}\} / \mathrm{P}\{\overline{\mathrm{E}} \mid \mp\}) \\
& =\log _{\mathrm{e}}((199 / 212) /(720 / 731)) \\
& =-\mathbf{0 . 0 4 8 2}
\end{aligned}
$$

\section{> Calculation of Evidential Theme Weights}

Likelihood ratios can indicate the following about the relationships between a layer of evidence and occurrences:

1. Positive correlation when $\mathbf{L S}>\mathbf{1}$ and $\mathbf{0}<\mathbf{L N}<\mathbf{1}$ - indicates that the layer of evidence is important positive evidence for the occurrences

2. Negative correlation when $\mathbf{L N}>\mathbf{1}$ and $\mathbf{0}<\mathrm{LS}<\mathbf{1}$

3. Uncorrelated: $\mathbf{L S}=\mathbf{L N}=\mathbf{1}$ - indicates that the probability of an occurrence would be unaffected the presence or absence of a layer of evidence.

\section{> Calculation of Posterior Probability}

\section{Prior Odds}

Defined as the ratio of probability of an event occurring against the probability that it will not occur, or:

$$
\text { In our case: } \quad \begin{aligned}
\mathrm{O}\{\mathrm{T}\} & =\mathrm{P}\{\mathrm{T}\} /(1-\mathrm{P}\{\mathrm{T}\}) \\
\mathrm{O}\{\mathrm{T}\} & =0.2243 /(1-0.2243) \\
& =0.2243 / 0.7757 \\
& =0.2892
\end{aligned}
$$




\section{- Calculation of Posterior Probability}

3. Conditional Posterior Logits (given presence or absence of layers of evidence)

Calculated as the natural logarithm (ln) of the conditional odds plus the positive or negative weight of evidence for each condition:

Posterior odds of an occurrence, given the presence of a layer of evidence

$$
\operatorname{logit}\{T \mid E\}=\operatorname{logit}\{T\}+W+
$$

Posterior odds of an occurrence, given the presence of a layer of evidence

$$
\text { logit }\{\mathrm{T} \mid \bar{E}\}=\operatorname{logit}\{\mathrm{T}\}+W \text { - }
$$

\section{- Calculation of Posterior Probability}

1. The probability of an occurrence based on the presence of a layer of evidence is the ratio of the odds of an event occurring against the odds that it will not occur based on the presence of a layer of evidence, or:

$$
\begin{aligned}
\mathrm{P}\{\mathrm{T} \mid \mathrm{E}\} & =\mathrm{O}\{\mathrm{T} \mid \mathrm{E}\} /(1+\mathrm{O}\{\mathrm{T} \mid \mathrm{E}\}) \\
& =1.2964 /(1+1.2964) \\
& =0.5645
\end{aligned}
$$

2. The probability of an occurrence based on the absence of a layer of evidence is the ratio of the odds of an event occurring against the odds that it will not occur based on the absence of a layer of evidence, or:

$$
\begin{aligned}
\mathrm{P}\{\mathrm{T} \mid \overline{\mathrm{E}}\} & =\mathrm{O}\{\mathrm{T} \mid \overline{\mathrm{E}}\} /(1+\mathrm{O}\{\mathrm{T} \mid \overline{\mathrm{E}}\}) \\
& =0.2614 /(1+0.2614) \\
& =0.2072
\end{aligned}
$$

The procedures outlined in the preceding paragraph are repeated for every class of every combination of layers of evidence and training points for each of the 120 tests conducted in this project. 


\section{Fixed Spatial Effects as Inputs into the WofE Model}

For the purposes of this paper, the layers of evidence will take the form of the identified fixed spatial effects based on, for the most part, proximities to certain physical features within the study area. This brings into play the question of what determines a suitable threshold for each and every one of the layers. If we look at the raw data, we see that the entire study area is within $n$ units of each physical feature deemed to be a fixed spatial effect. This is not a very useful level of input into the WofE model, as the each layer will generate a $\mathrm{W}+$ and no $\mathrm{W}$ - for the entire study area. Fortunately, there is a simple way around this. But first we must provide some brief explanation of the methodology used to massage the data for analysis within the WofE model.

As noted in the previous section, several calculations must be made in order to assess posterior probability based in any layers of evidence and any training data layers. I have referred to these data as "layers" due to the fact that the data can be represented in two dimensions in the form of a map. Using a commercial GIS software package (ArcView 3.2 with Spatial Analyst), the requisite transformations were made to raw geospatial land use data in order to generate layers of evidence based on fixed spatial effects of residential B\&Es as defined in this paper. Fortunately, the development of an ArcView 3.2 compatible "Weightsof-Evidence Extension" was prepared by a group led by the very scientist responsible for creating the model as it is being used here. Bonham-Carter's 
group at Natural Resources Canada's Geological Survey of Canada, along with counterparts at the U.S. Geological Survey, developed this extension and made it freely available over the Internet at http://ntserv.gis.nrcan.gc.ca/wofe/.

Given that each and every calculation is automated within the GIS and the WofE extension, it is necessary, in developing a suitable posterior probability map, that the raw data is formatted in an appropriate manner for further analysis. As stated earlier, determination of suitable thresholds for each layer of evidence representing each identified fixed spatial effect was necessary. Core functionality of ArcView 3.2 with the Spatial Analyst extension enabled these data transformations for input into the WofE model.

Base geospatial data layers supplied to Ottawa Police Service by the City of Ottawa enabled the development of a series of proximity maps based on the noted fixed spatial effects. This data includes the following: the street centerlines layer, the property parcel layer (for land use categorizations) and the recreational trail layer - all in ESRI Shapefile format and all current as of July 2004. The proximity maps were developed using ArcView and Spatial Analyst to determine the distance of each discrete $25 \mathrm{~m} \times 25 \mathrm{~m}$ grid of land within the study area to each of the physical features noted as the roots of fixed spatial effects. Each proximity layer was then reclassified into 48 equal interval classes that were then fed into the WofE model to generate unique $W+$ and $W$ - values for each class in each layer. The determination of thresholds comes from using a WofE measure 
contrast, which is simply the difference between $\mathrm{W}+$ and $\mathrm{W}$ - for each and every one of the 48 classes in the layer. The raw contrast measure is interesting, but Bonham-Carter notes that a more meaningful determination of layer thresholds comes from the enhanced contrast measure called "studentized contrast" (sC), which is the contrast of each class divided by its standard deviation (BonhamCarter, 1994). When the $\mathrm{sC}$ reaches a maximum, the cumulative distance associated with this maximum value indicates a suitable threshold for binary reclassification (pattern present within study area/pattern not present within study area). A binary reclassification of a layer of evidence essentially determines where a pattern is present or where a pattern is absent within the study area. This binary reclassification is repeated for every layer of evidence being used as inputs, and $\mathrm{W}+$ and $\mathrm{W}$ - are then recalculated for each of the reclassified binary layer and fed into the final posterior probability calculation. The following illustration brings this process into a clearer light:

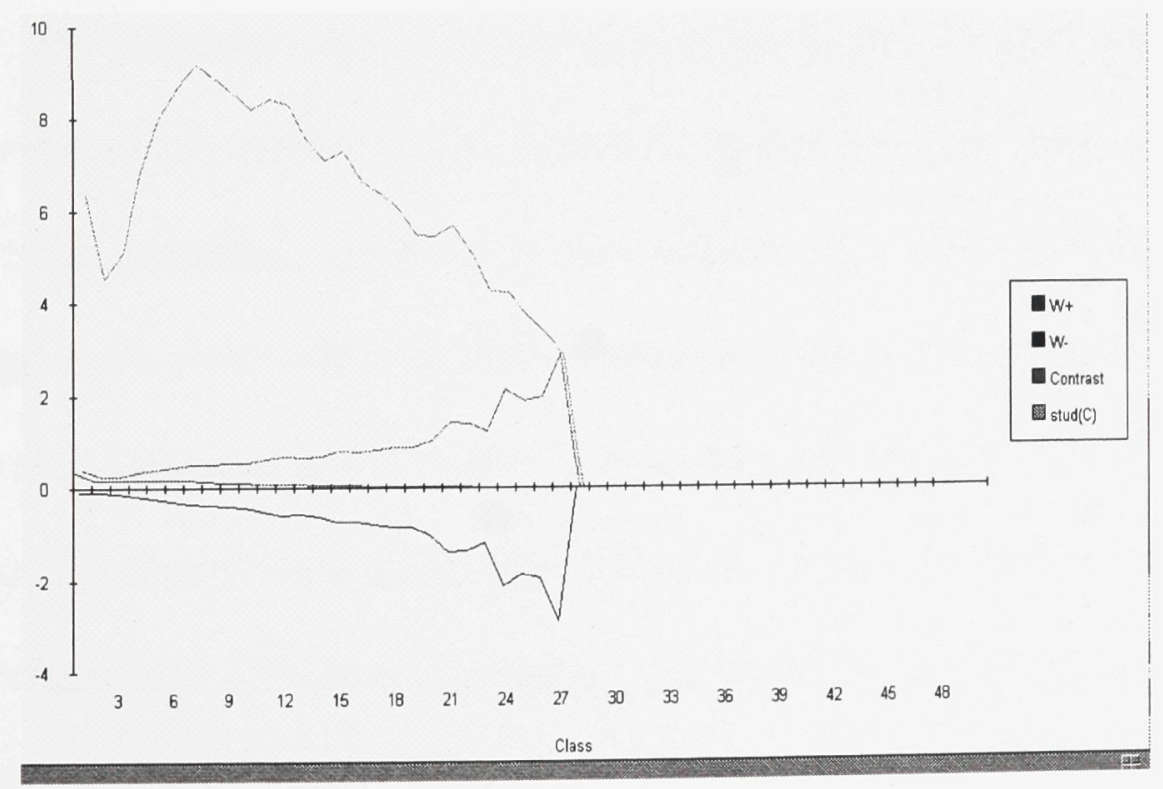

Figure 5 Illustration of W+ and W- for $\mathbf{4 8}$ classes plotted with sC 
As is evident in this graphic, as the class number (and distance away from physical feature) increase, the $W+$ and $W$ - values vary accordingly. We can also see that Contrast varies through the progression of the classes (as distance increases). More explicit is the variation in the $\mathrm{SC}$ and how this value peaks at around Class 7 . This indicates a suitable threshold for binary reclassification for this layer of evidence. Since the class value is tied to a specific range of proximity for each layer, threshold distance can be easily determined for each layer.

The posterior probability map produced by the GIS-based weights-of-evidence model is what I am calling a "crime potential map" (CPM). Since the Bayesian approach addresses the problem of combining datasets in a probabilistic framework, the results of this research project will avoid any concerns regarding environmental determinism vis à vis the offender and the occurrence of crime. Additionally, the Bayesian approach considers the notion of prior probability: that the occurrence of an event in the future is dependent on past history, in the context of crime potential modeling. If we experience 2000 residential break and enters a year in an area with 100,000 residences, the prior probability of any one residence being targeted is $2 \%$ in any given year. A value as low as this for prior probability does not provide much assistance in either law enforcement or crime prevention initiatives. Posterior probability accounts for additional factors that will indicate a non-uniform distribution of probability, given the theoretical support given to certain types of fixed spatial effects. A single residence may, in fact, 
have a very high probability of being hit by a break and enter due to any number of factors as identified in the theoretical overview including location of recent known break and enters and the location of any given residence in relation to certain types of fixed spatial effects. Likewise, another single residence may have a significantly lower risk due to these same considerations. This research uses the weights-of-evidence model called Arc-WofE in ArcView 3.2 as the tool to provide an estimate of the potential that any given small unit area will have for the occurrence of crime, based on where known locations of recent break and enters analyzed in conjunction with specific relevant fixed spatial effects 


\section{Chapter IV - Research Design and Methodology}

This research project is situated within the urban core of the City of Ottawa, Ontario, Canada and employs both crime data and land use data that is available through the City of Ottawa and the Ottawa Police Service. The principal researcher is a member of the Ottawa Police Service and holds the position of Resource/GIS Analysis Coordinator within the Corporate Planning Section of the Service. It has been through the work being done by the researcher in this position that the gap in academic knowledge in crime potential mapping was identified and the applied use of any meaningful outcomes from this research could be realized. The researcher is also responsible for conducting spatial research in the area of crime analysis and this particular study falls directly into that realm.

\section{Methods}

This project employs two methods to answer each of the research questions posed earlier in this report. First, a comprehensive literature review was conducted that critically assesses the theories relevant to this study as well as identifying and extracting discrete land use types that act as fixed spatial effects in this body of work - these are outlined in Chapter II. Second, in order to determine the optimum aggregate arrangement of fixed spatial effects in the GISbased weights-of-evidence model to produce a reliable crime potential map, a quasi-experimental research design is employed. In order to set up a reliable 
method of prediction, it is necessary to collect data specific to the weights-ofevidence model over a longitudinal time span (at a variety of intervals) to provide a strong basis for isolating those areas within the study area that have a greater potential for crime at any given time. The idea here is to determine the optimum arrangement of spatial proximities related to a number of land use types with a certain amount of evidential crime data as a support. One of the questions that needs to be answered is: "How many known occurrences of residential break and enter are necessary to prime the weights-of-evidence model in order to generate a reliable crime potential map that can be used to isolate those areas with a greater potential?"

\section{Data Needs}

The study area covers a $136.1 \mathrm{~km}^{2}$ plot of land in the urban core of the city of Ottawa and is generally concurrent with the boundaries of the former municipality of Ottawa prior to municipal amalgamation. The study area is a mixture of residential and commercial development with a greater proportion of institutional land use to industrial land use. 


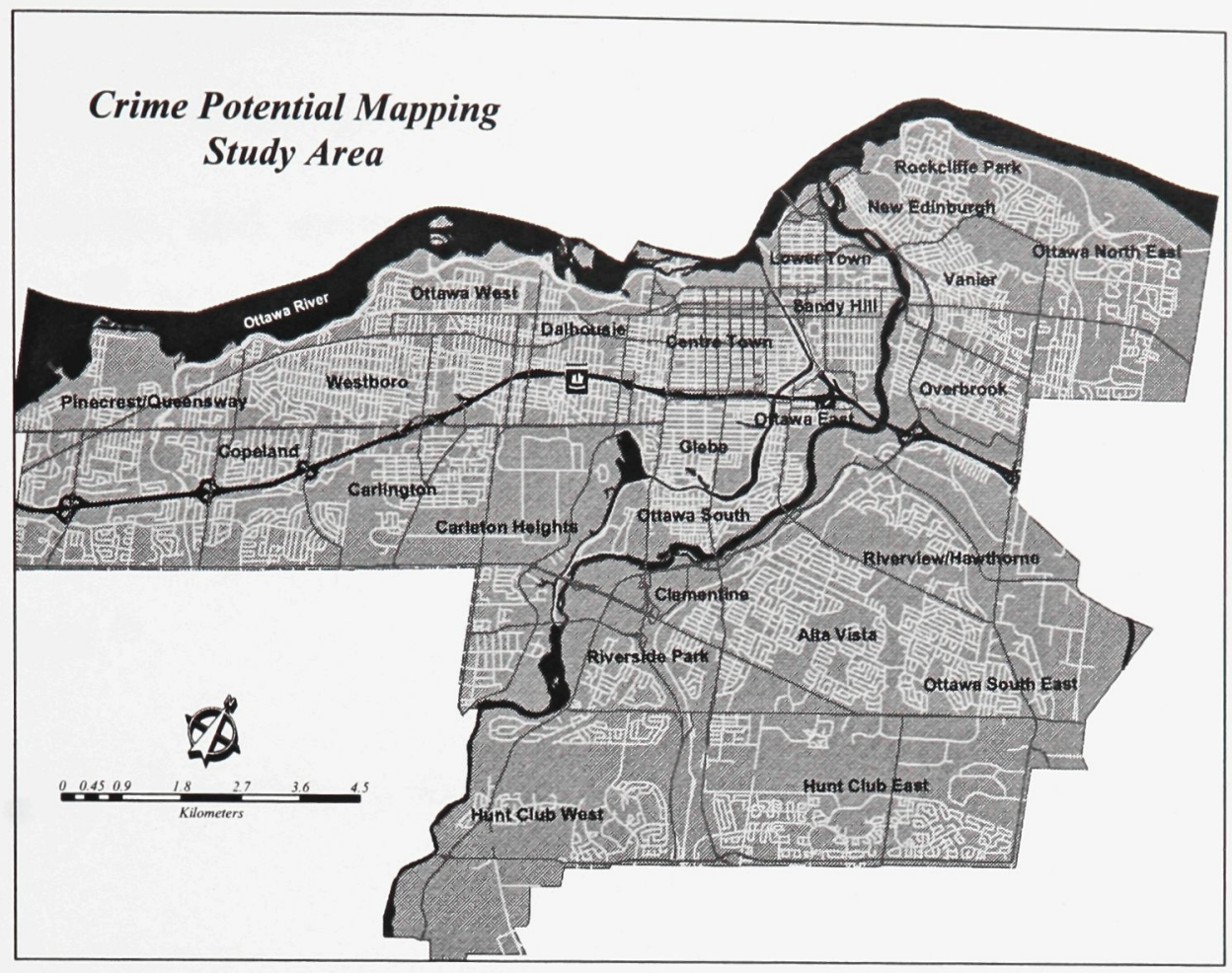

\section{Figure 6 - Map of Study Area}

There are approximately 112,000 unique dwellings of all types in the study area. The two main reasons for this choice of study area are that: a. very little land use change has taken place in this study area since 1996; and, b. all necessary and adequate data for this area are available. While crime data related to break and enters is available in a useable format, digital land use maps are not continuously available for the entirety of the city at this time. The land use data coverage is continuous within the chosen study area. Since there is a temporal component to this research project, it was decided to limit the experimental framework to crime data that occurred between January 1, 2000 and December 31, 2002 in the aforementioned study area boundaries. The reasoning for this approach is the desire to be consistent with the land use maps that are available for the area; the last digital land use maps were updated in 1998. This area of the city is a well- 
developed and mature part of the urban landscape and as such there is very little land use change to be accounted for within the scope of this project. The residential break and enter data set for this time period is deemed to be satisfactory in terms of both accuracy and in size - crime data is mapped to the block face in the city of Ottawa and there is enough volume on a week to week basis in the study area to ensure adequate support in the statistical analysis that will take place.

\section{The Weights-of-evidence Model}

A posterior probability map is generated as the result of calculating the four states of conditional probability between the various combinations of layers of evidence and training data and then performing a series of probability and oddsbased transformations within the GIS-based weights-of-evidence model. If the various fixed spatial effects are considered to be layers of evidence and known locations of residential break and enters are considered to be training data, the weights-of-evidence model assesses the state of the four conditions for each fixed spatial effects, calculates the weight measurements for each layer, combines all layers into a "unique conditions map" and performs a number of statistical transformations on this information to generate a map of probabilities for each unique condition small unit area.

Simply put, the GIS-based weights-of-evidence model takes the various measures of conditional probabilities for each of these conditions for each of the 
fixed spatial effects layers and the various subsets of break and enter training data to generate a series of posterior probability maps (in weights-of-evidence terms) which this body of work calls a "crime potential map". The performance and accuracy of these crime potential maps will then be compared to the next in a series of events (i.e., the next week's locations of occurrence of residential break and enters) to determine the optimal configuration of layers of evidence (fixed spatial effects) and evidential layers (known locations of recent break and enters) within the GIS-based weights-of-evidence model. In order to accomplish this feat, a proper experimental framework must be implemented.

\section{Experimental Design}

The desired outcome of this research is to determine the optimal arrangement of layers of evidence, in conjunction with an appropriate inclusion of training data to generate a reliable crime potential map on a periodic basis to account for both the spatial and temporal variation in crime potential within the study area. The desired period in this case is set at one week (seven days); if a reliable prediction can be made for the coming week, there is a reasonable degree of utility at the operational level. If a "break and enter response team" wanted to determine their strategy for the next week, a weekly crime potential map would be a support tool for this function. That said, the structure of the experimental design must support the desired outcome. So, what is the required input to produce a weekly crime potential map for Break and Enters? 
Since crime is not a static phenomenon - crime has been shown to move around in seemingly random patterns when observed on a week-to-week basis - then an experiment must be devised to account for week to week changes in activity. The quasi-experimental design (with non-equivalent groups) is used to determine the sampling framework, the treatment method as well as the measures of outcome. The major steps in the experiment are deemed to be:

1. Initial Exploratory Spatial Data Analysis (using the GIS-based weights-ofevidence model) to determine the optimal proximity thresholds for each key land use to develop fixed spatial effects maps to be used as layers of evidence in further modelling.

2. Determine the optimum sample size of known break and enter occurrences to produce a sufficient degree of probability (i.e., greater than $66 \%$ for any time period) in the crime potential map that is produced by the weights-of-evidence model using the previously determined fixed spatial effects maps. A scatter plot analysis will be used to plot number of training points against maximum posterior probability for each and every test in the experiment. Test periods were set at pre-determined intervals for the three-year period to generate a sufficient data set for further analysis. The determination of the optimum sample size will start with the inclusion of one week's worth of training data and then work backwards 
until no significant improvement in posterior probability is shown. Initial analyses showed that about 300 training points are required to generate a crime potential map that has a maximum probability measured at least at $90 \%$ for at least a small portion of the study area. The 300 training point support represents about eight weeks of training data, meaning that in any given week, the last eight weeks of occurrences must be collected in order to prepare a crime potential map for any coming week. This type of dataset is deemed to be the "non-equivalent group" as an 8-week sample will not always supply exactly 300 training data points. The following chart summarizes the sampling and testing framework on a temporal basis.

\begin{tabular}{|c|c|c|}
\hline Year & Test Weeks & Sample Size (Weeks) \\
\hline 2000, 2001, 2002 & 10 & $1,2,3,4,5,6,7,8$ \\
2000, 2001, 2002 & 20 & $1,2,3,4,5,6,7,8$ \\
2000, 2001, 2002 & 30 & $1,2,3,4,5,6,7,8$ \\
2000, 2001, 2002 & 40 & $1,2,3,4,5,6,7,8$ \\
2000, 2001, 2002 & 50 & $1,2,3,4,5,6,7,8$ \\
\hline
\end{tabular}

Table 1 Sampling Framework

For example in 2002, Week 20 was tested 8 times: using 1 week of training data (backdated from the end of the previous week); using two weeks of data, and so on through 8 weeks of data. So, for each of the three years in the study period, and each of the 5 test points in each year, there will be $5 \times 8 \times 3$ observations for a total of 120 test observations. As stated in the previous paragraph, the sample size of any one set of weeks of training data ( 1 week through 8 weeks) will not necessarily be the same size. As stated in a previous section, the range of frequencies for a one- 
week period in the study period ranged from a low of 8 to a high of 116 in any given week. For the 8-week periods in the study, this frequency ranged from a low of 111 occurrences to a high of 442 occurrences, hence the need for the non-equivalent group experimental design. From this framework, the WofE model was run for each slice of data against each and every layer of evidence in combination so the cumulative weights for all layers of evidence would be combined into one crime potential map (map of posterior probabilities for each $100 \mathrm{~m} \times 100 \mathrm{~m}$ grid cell in the study area). For each temporal test point, the following data was collected:

- Total number of points in the training data set as discrete occurrences - Num_TP

- The maximum measure of posterior probability supplied by the resulting crime potential map - MaxPP (Grid)

See Appendix A for a summary of these results in tabular format.

3. Determination of the accuracy of the crime potential map; this entails the collection of a number of data observations at each test point. A framework was created to collect performance data based on the framework as described in this previous paragraph. To determine the accuracy of the prediction, we must see that a certain proportion of future occurrences fall within a certain range of probability. Both thresholds were set at $66 \%$ - if we see that $66 \%$ of the next week's occurrences fall in 
areas where the posterior probability range is between $66 \%$ and $100 \%$, we can be assured that a good prediction has been made and the crime potential map can be used. These thresholds were set as a rule of thumb and did not change based upon the analysis results. The lowest possible threshold would be $50 \%$, as a probability level of $50 \%$ indicates that a prediction has no better chance than a prediction made at random. There is certainly the danger that a poor prediction can be made in any given week, so the frequency of satisfactory performance will be tracked as well. The following data was collected for each test point:

- The maximum posterior probability from the crime potential map occurring at the actual point of occurrence from the test data set in the next week. MaxPP (Obs)

See Appendix A for a summary of these results in tabular format.

Given that each of these steps produces meaningful results, this process has produced a useful operational tool at the tactical level for local law enforcement. It is entirely possible that meaningful results may be difficult to obtain using the variables as defined in this analysis using data from another place and/or time. In the event of this happening, it is possible to perform the analysis again after adjusting any of the input variables: it may require an adjustment of the proximity thresholds for any and all fixed spatial effects maps, it may require the exclusion of certain combinations of fixed spatial effects maps or it may require the use of more or less training data in each test. 


\section{Chapter V-Results of Analysis}

\section{Initial Exploratory Spatial Data Analysis}

The area of study encompassed the boundaries of the old cities of Ottawa, Vanier and Rockcliffe. As well, the area within these boundaries represents, in general, the current "urban core" of the City of Ottawa. While not homogenous in structure, the study area does not contain any large new suburban areas, any large tracts of agricultural land save for the Central Experimental Farm, nor does it contain any overtly rural non-agricultural land uses. Approximately $30 \%$ of the study area is comprised of residential land use of various densities. The frequency of residential break and enter occurrences by week ranges from a low of 8 occurrences in Weeks 6 and 7 in 2000 to a high of 116 occurrences in Week 50 of 2002. It is evident that the frequency of this type of crime is quite variable when measured as counts per week. In fact, there is a distinct seasonality to the occurrence of residential break and enters with the warmer months experience a greater frequency of occurrence by week and the colder months experiencing fewer occurrences by week. The following chart summarizes this seasonality over the course of a five-year period ending December 31, 2004 on a month-bymonth basis. 


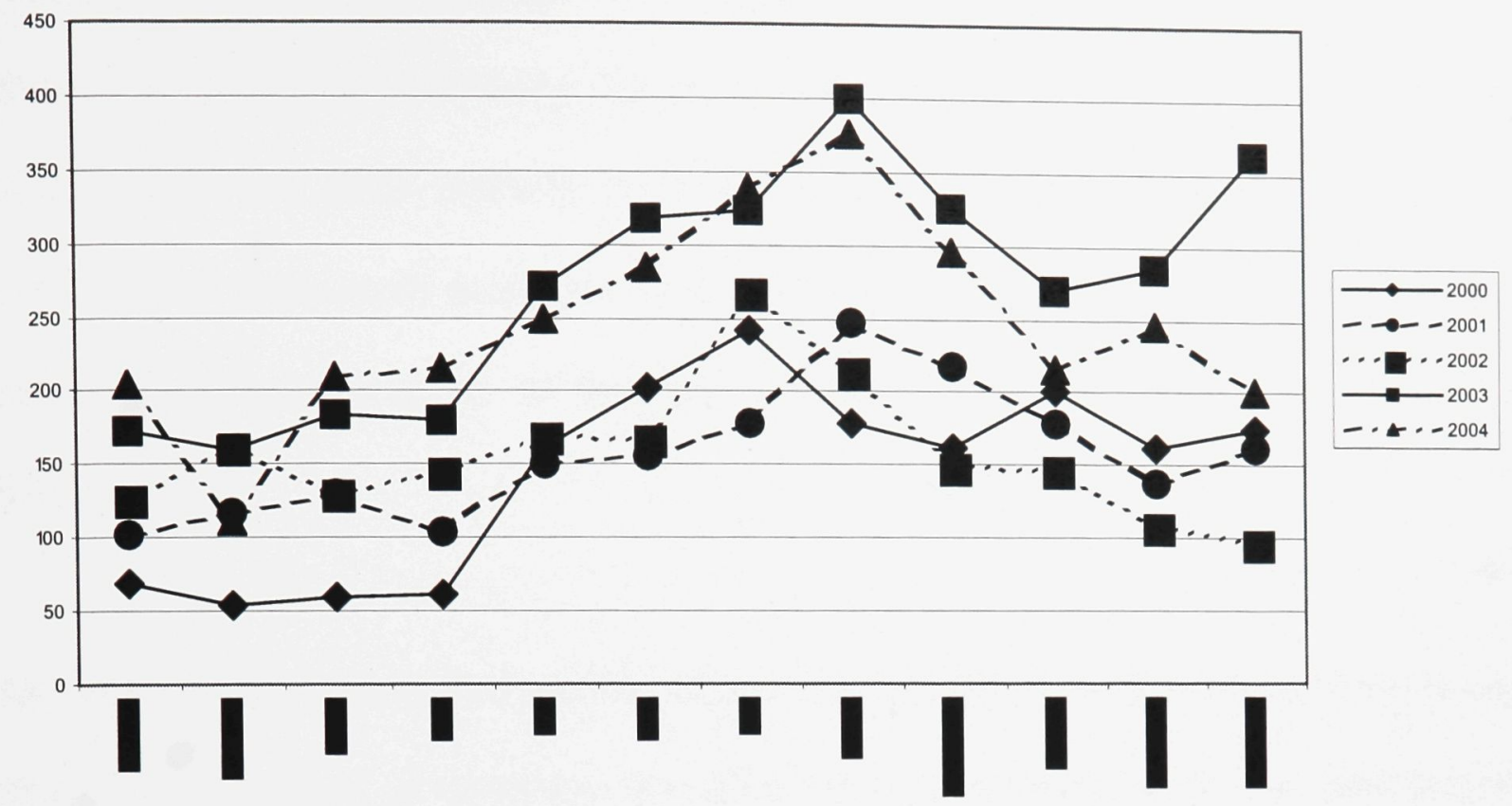

Figure 7 - Long Term B\&E Trends in Ottawa

These crime occurrence details, which function as training data for the WofE model, were extracted from the Ottawa Police Service computerized Records Management System (RMS) and reflect each and every residential B\&E that occurred within the bounds of the study area during the year 2001. Details extracted included the date and time of occurrence, address, $x$ - and $y$ coordinates (for spatial referencing), and offence type. This data represents a total of 1851 occurrences for that time period in that area and each occurrence was plotted into a map of the study area. For reasons of privacy, these data will not be included in this report in any detail.

This data represents a prior probability of approximately $13 \%$ based on the initial calculations for the WofE model. Improving on this measure of prior probability using the appropriate fixed spatial effects is the goal in this analysis. A prior 
probability of $13 \%$ is very low - an analyst has slightly more than a 1 in 10 chance of spatially predicting the occurrence of residential B\&Es in this study area, based on 2001 training data. If we can run the model so that we can improve the maximum posterior probability to exceed $50 \%$ to $60 \%$, we have a better than even chance of spatially predicting the occurrence of residential B\&Es.

As noted earlier, base geographic data was sourced from the city of Ottawa and this data was used to generate the proximity layers that define the fixed spatial effects required to generate a meaningful posterior probability map. This section will briefly document the methodology used to generate these proximity maps, and the values generated to determine binary reclassification thresholds for each layer of evidence for input into the model.

1. Proximity to commercial land use - based on 1995 digital land use compiled by the city of Ottawa level. Land uses that included pure commercial, shopping and industrial land uses were included.

2. Proximity to vacant land use and parkland - based on 1995 digital land use maps by the city of Ottawa. A discrete "vacant" land use class was already present and extracted. 
3. Proximity to main thoroughfares - based on city of Ottawa digital street network file current as of January 1, 2002. Main thoroughfares were defined as those roads in the city that are considered to be "Regional/County Roads", "Federal Parkways", "Transitways" or "Provincial Highways".

4. Proximity to 4-node intersections - based on all streets in the city of Ottawa digital street network file. 4-node intersections were defined as those intersections having a 4-way intersection of 2 or more streets. There were a small number of 5- and 6-node intersections in the study area, as well as 1-node (cul de sacs), 2-node (two streets that butt against each other) and 3-node (t-intersections, for example) intersections. A separate ArcView extension called "Point and Polyline Tools v.1.2" was used to prepare this data into a suitable format.

5. Proximity to pedestrian thoroughfares (urban trails) - based on current city of Ottawa digital geographic files - "Trails"

6. Land use type by housing density class - based on 1995 digital land use maps by the city of Ottawa - there were 8 unique nominal classes in this layer ranging from "single family detached" class to "apartment $>5$ floors" class. 
Each of these layers was run in the WofE model ArcView extension and assessed for suitable thresholds. The following chart summarizes the various statistics for each layer of evidence. Suitable proximity thresholds for each layer of evidence are detail in the Max stud C column.

\begin{tabular}{|l|c|c|c|}
\hline \multicolumn{4}{|c|}{ Max Prox Interval Max stud C } \\
\hline Commercial & $2316 \mathrm{~m}$ & $48 \mathrm{~m}$ & $289 \mathrm{~m}$ \\
\hline Trails & $1820 \mathrm{~m}$ & $38 \mathrm{~m}$ & $684 \mathrm{~m}$ \\
\hline Main Roads & $2121 \mathrm{~m}$ & $44 \mathrm{~m}$ & $308 \mathrm{~m}$ \\
\hline $4-$ Nodes & $1732 \mathrm{~m}$ & $36 \mathrm{~m}$ & $98 \mathrm{~m}$ \\
\hline Parks/Vacant & $1755 \mathrm{~m}$ & $36 \mathrm{~m}$ & $360 \mathrm{~m}$ \\
\hline Recreational & $1708 \mathrm{~m}$ & $35 \mathrm{~m}$ & $280 \mathrm{~m}$ \\
\hline
\end{tabular}

Table 2 Statistics for each layer of evidence

Initial ESDA has shown that the measure that indicates the optimum proximity threshold does not change to any significant degree for any period under consideration during the three-year period. This tells us that the proximity thresholds are relatively stable regardless of the time of year. This is good news because no further analysis is warranted other than determining the optimum thresholds for each of the key leading indicators.

Therefore, where Studentized Contrast was at its maximum, the binary classification threshold was set at that distance of proximity as defined in the preceding table. The following are a series of charts and maps for each layer of evidence that were used in the WofE model. Each layer was reclassified in 
ArcView to reflect these binary thresholds. The WofE model was run again against these newly reclassified layers and a new posterior probability map was generated. The following table summarizes the binary $W+$ and $W$ - values for each layer of evidence based on the preceding thresholds.
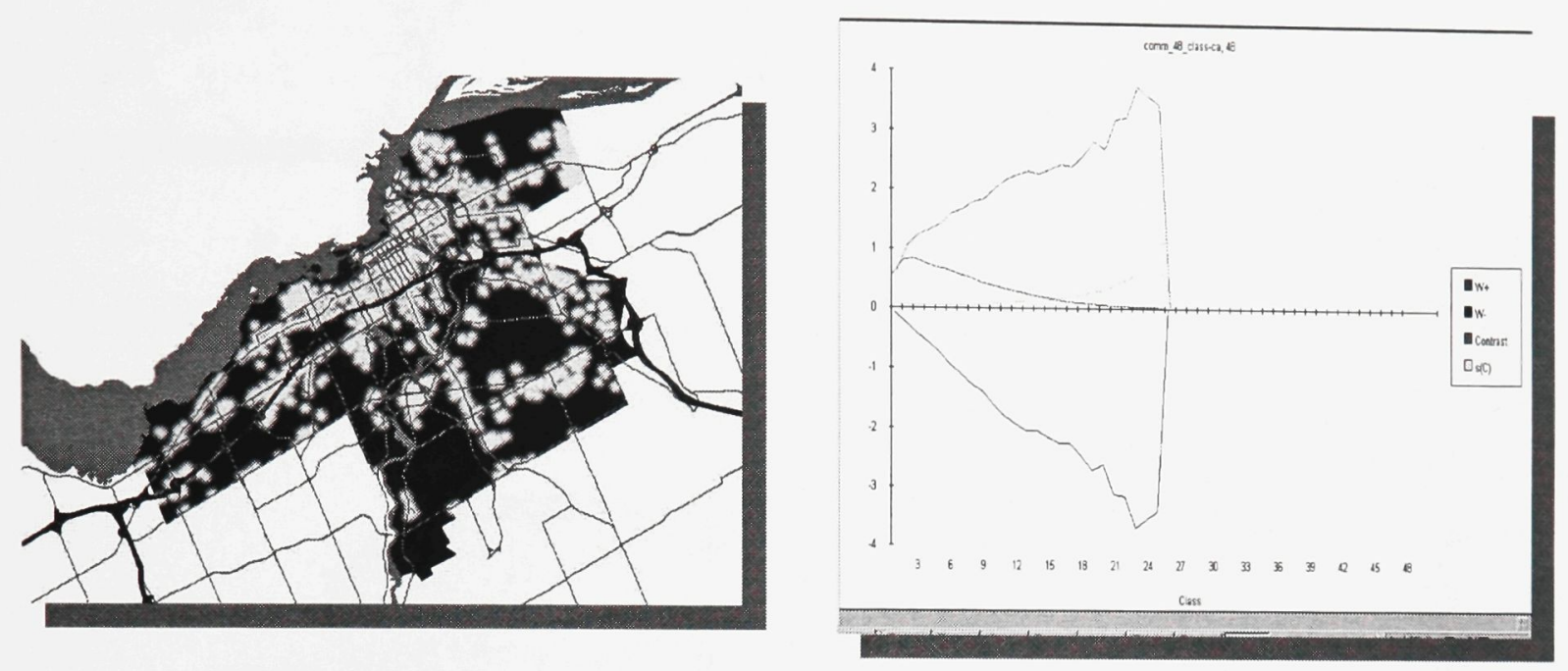

Figure 8 Proximity to Commercial Land Use / W+, W- , C and stud C chart
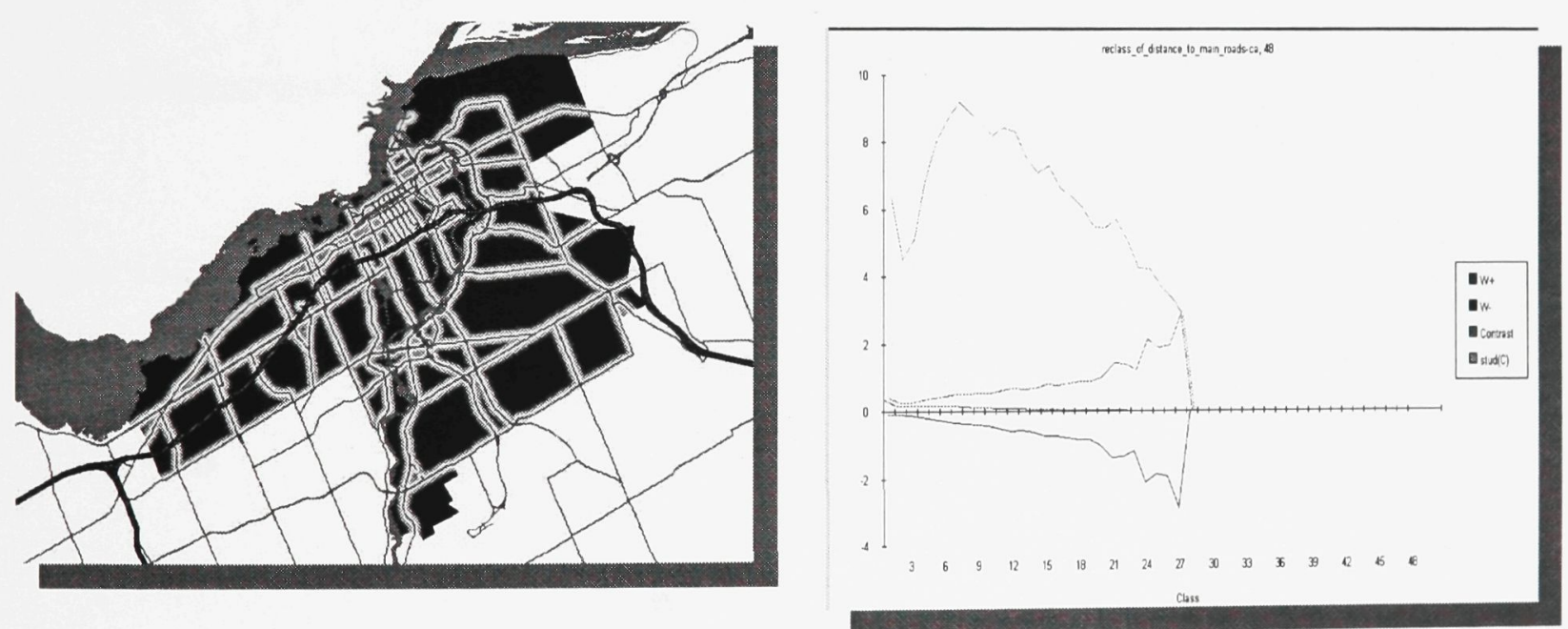

Figure 9 Proximity to Main Roads / W+, W- , C and stud C chart 

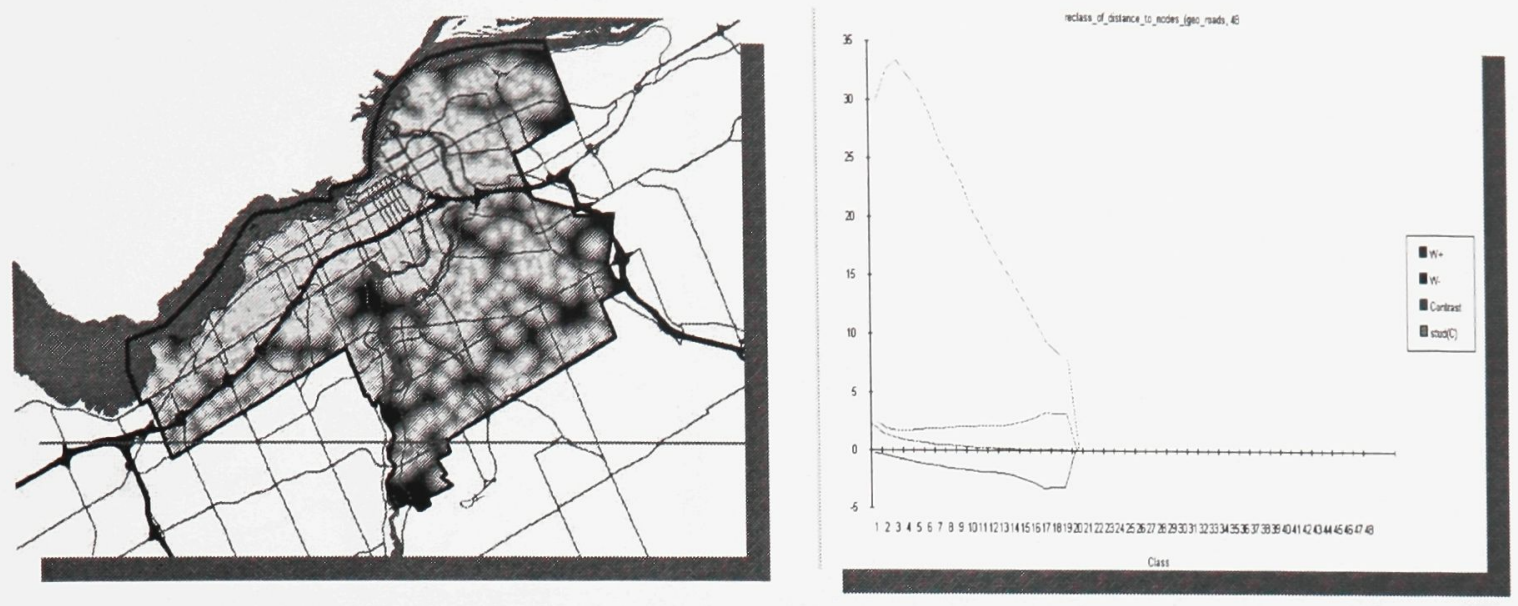

Figure 10 Proximity to 4 Node Intersections / W+, W- , C and stud C chart
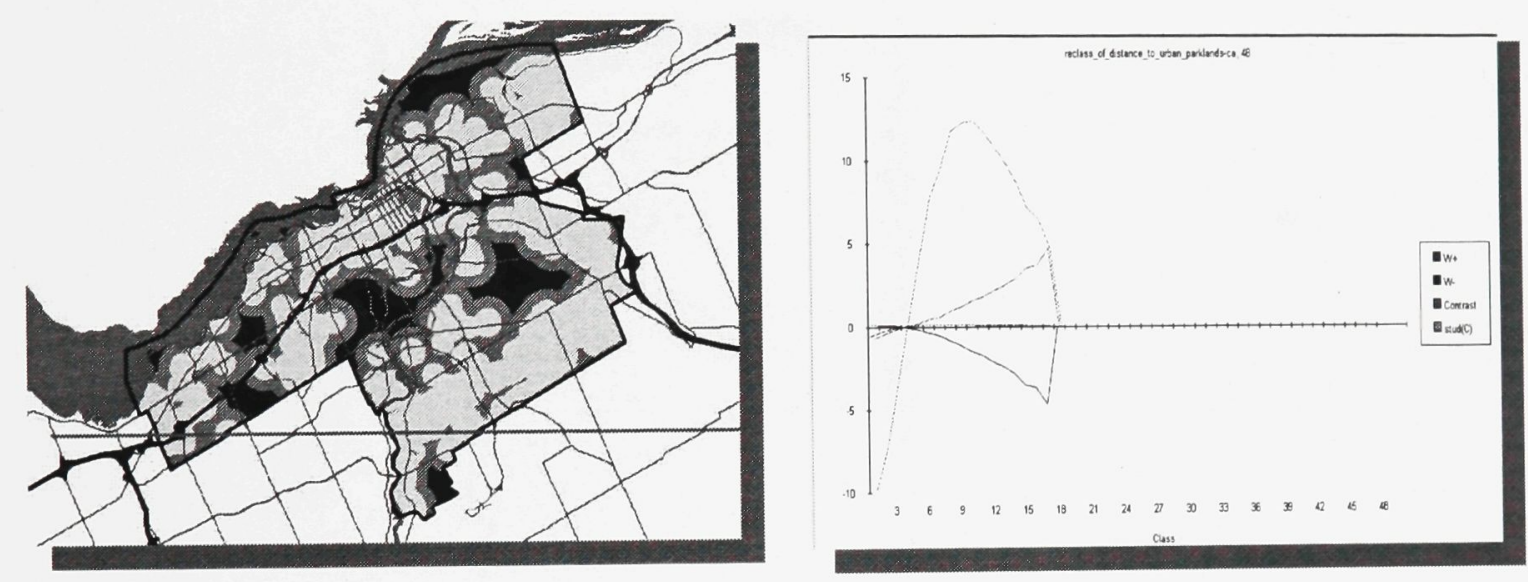

Figure 11 Proximity to Vacant Land/ Parkland / W+, W- , C and stud C chart 

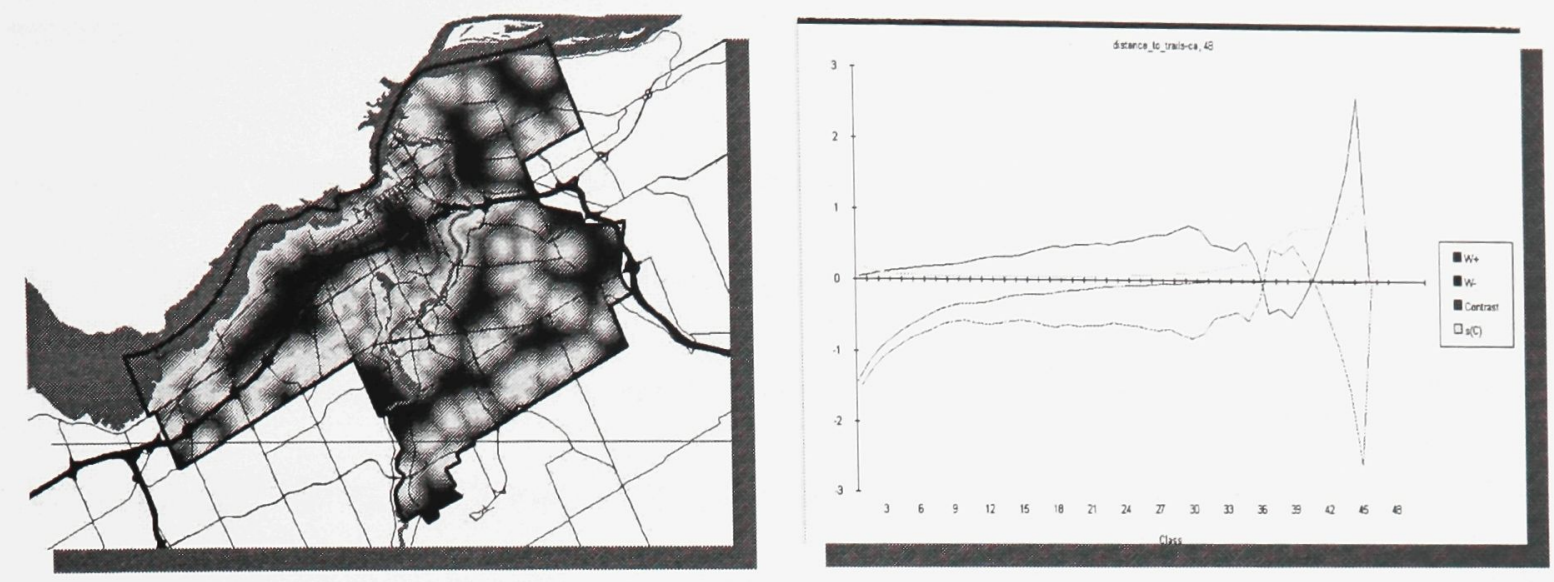

Figure 12 Proximity to Urban Trails / W+, W- , C and stud C chart

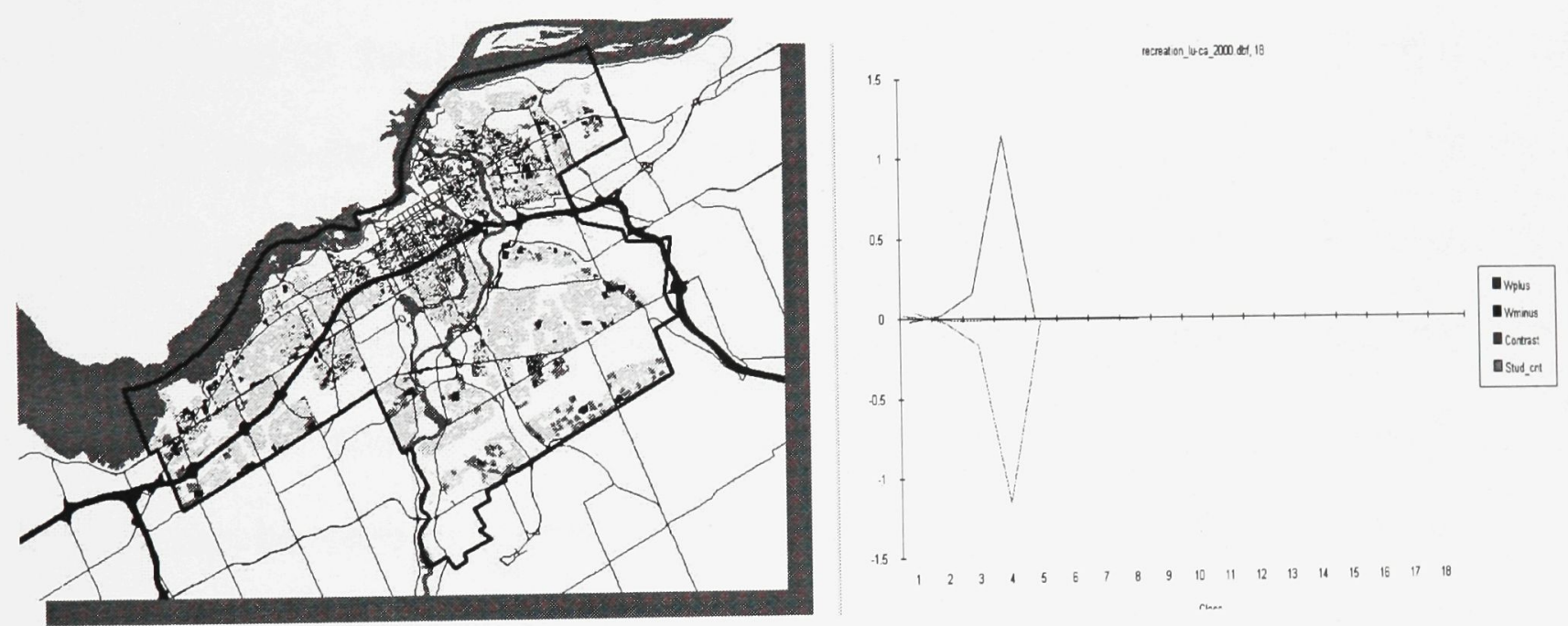

Figure 13 Recreational Land Use/ W+, W-, C and StudC chart

\begin{tabular}{|l|c|c|c|}
\hline \multicolumn{1}{|c}{ Layer } & $289 \mathrm{~m}$ & 0.6519 & -0.9411 \\
\hline Commercial & & & W- \\
\hline Trails & $684 \mathrm{~m}$ & -0.1847 & 0.4748 \\
\hline Main Roads & $308 \mathrm{~m}$ & 0.1672 & -0.3436 \\
\hline 4-Nodes & $98 \mathrm{~m}$ & 1.1367 & -0.6188 \\
\hline Parks/Vacant & $360 \mathrm{~m}$ & 0.1301 & -1.14115 \\
\hline Recreational & $280 \mathrm{~m}$ & 1.4652 & -0.0075 \\
\hline
\end{tabular}

Table 3 Overall $\mathbf{W}+$ and $\mathbf{W}$ - values for each layer of evidence (full year 2000) 
*Individual Class weights $(\mathrm{W}+$ and $\mathrm{W}-)$ for each residential land use density were calculated separately for each class and do not fit in this chart

As can be seen in Table 2, individual layer weights varied by layer and by threshold. This is a desired effect in the WofE model. Notice that the numeric signs of $\mathrm{W}+$ and $\mathrm{W}$ - values are reversed for the Trails layer $(\mathrm{W}+$ is a negative number and $\mathrm{W}$ - is positive). This indicates that the spatial relationship is opposite to what was expected - the pattern/deposit relationship is reversed. Also note the absolute values of $\mathrm{W}+$ and $\mathrm{W}$-. As is evident in the preceding chart, most of the layers show a moderate to strong predictive capability. This is a good indication that the choice of fixed spatial effects that were included in this model were suitable, as were the binary classification thresholds assigned to each layer. The goal of this portion of the research was to assess the validity of using the WofE model, in conjunction with knowledge gained from the literature regarding meaningful fixed spatial effects to generate a meaningful posterior probability map that can be used to predict the occurrence of residential B\&Es in this study area. I feel that this goal has been met and the data explored here can be used to further refine and enhance the inputs of the model to include more fixed spatial effects and to include controls for the dynamic nature of crime over time. 


\section{Optimum Sample Size Analysis/Temporal Analysis}

Using the data collected in the test runs of the WofE model as detailed in the previous section, the maximum posterior probability was collected for each crime potential map that was generated. This information was stored in a spreadsheet and the summarized results are presented here. For each test run of $1 . .8$ weeks for each test period (Week 10, 20, 30, 40 and 50) for each year, we observed the following trends.

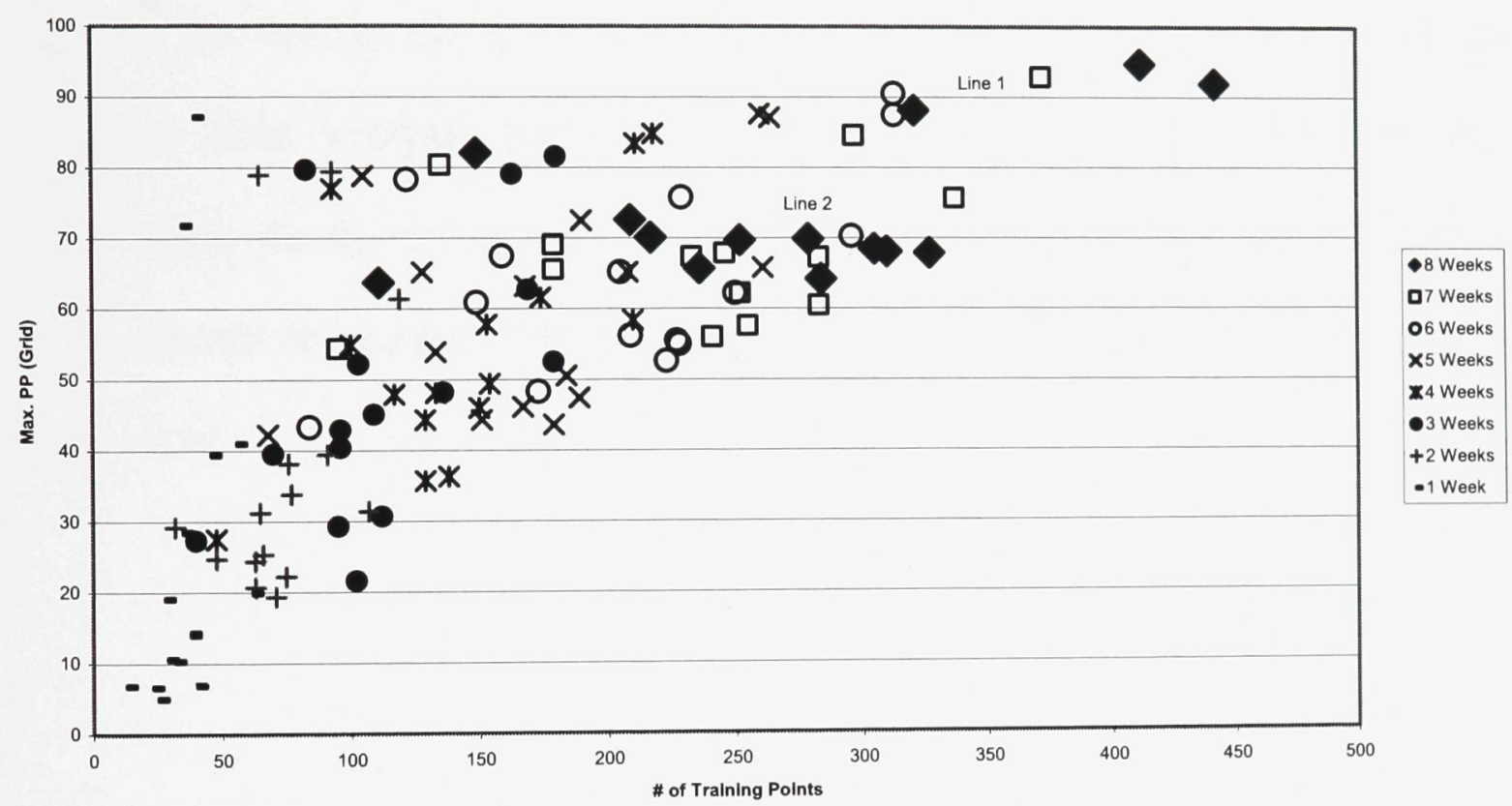

Figure 14 MaxPP Output

As is evident in this chart, there is a distinct trend in the observations obtained that the greater the number of training points in the dataset, the greater the measure of maximum posterior probability in any one crime potential map. There actually seem to be two patterns evident in the data as well - one where the slope of the MaxPP to Number of Points seems to be fairly flat at the $80-95 \%$ 
line. The other shows a steeper slope, but the MaxPP tops out at about $75 \%$. Of prime concern, though are the observations where MaxPP exceeds the $66 \%$ threshold mentioned earlier. Generally, it requires about 8 weeks of training data to accomplish this, based on these observations. I know that not all 8-week periods in the study contain the same number of training points, so this is a rough guide at best. However, the 8-week rule of thumb was carried forward since the 8-week period was the only period that consistently delivered a MaxPP that exceeded about $66 \%$ for each and every test run. The 8 -week threshold also seems to be where the point of diminishing returns kicks in, based on the exploratory data analysis that was conducted prior to this particular research project. Since we do not expect to ever obtain a 100\% MaxPP in any of the test runs, it stands to reason that there would be no need to include extraneous training data. 


\section{Performance Assessment of WofE}

Although this thesis has shown the utility and effectiveness of the WofE model in generating a spatial prediction of where future occurrences of residential break and enters MAY occur given an optimal arrangement of training data and layers of evidence, it remains to show how accurate the predictions for each of the test points fared against actual data. As stated in the Methods section of this paper, the data in the week that was being tested was compared against the crime potential map that was generated for that week via the WofE model in ArcView and based on the combination of the layers of evidence and the 8-week training data series for that week. The hypothesis of accuracy is quite simple: if a test point for the week falls into an area where the posterior probability is at or near the MaxPP, then that prediction was a success. The MaxPP for the crime potential map was captured (MaxPP Grid), as was the measure of MaxPP for any of the test occurrences in the week being tested (MaxPP Obs). An ancillary measure of Diff (MaxPP Grid - MaxPP Obs) was generated to illustrate the accuracy of the crime potential map. A measure of difference of zero (0) indicates a very good level of accuracy while a positive measure well beyond zero $(0)$ indicates a poor level of accuracy. Based on the observations collected for the 8-week test runs, we found that the minimum difference of zero occurred 3 times in 15 tests. The average difference for the 8-week test points was 7.2 and the maximum difference was 17 . In fact, 11 of 15 observations had a difference in MaxPP Grid to MaxPP Obs of 10.0 or less. This bodes well for the accuracy of the model and its inputs in that the predictions, using 8 weeks worth 
of training data, exhibit a great deal of accuracy on a spatial level. To wit, at least one of the test points was located in an area that defined as having a posterior probability within at least $10 \%$ of the MaxPP of the entire crime potential map. The more accurate predictions were made more frequently in Weeks 20, 30 and 40 than in weeks 10 and 50 regardless of the number of training points used as inputs to the model. As well, the year 2000 generated more accurate predictions than 2001. Additionally, 2001 generated more accurate predictions than in 2002 regardless of the number of training points used. For the first issue, seasonality is a first guess at an underlying mechanism that could affect the accuracy of the model. Does offender use of space change significantly enough in the warmer months to precipitate a change of some sort in this model, or at least the accuracy of this model using these methods? For the second issue, the raw counts of B\&Es in 2000, 2001 and 2003 don't provide a basis for explanation of this accuracy issue. What does perhaps point us in the general direction of an explanation is the fact that B\&Es in 2000 were more heavily clustered in the warmer months of the year.

The following maps show the progressing of data analysis in the WofE environments, starting with the raw break and enter point locations (Fig 15) for Week 20 2000, through the resulting crime potential map for the study area (Fig 16), the scope of residential land use within the study area (Fig 17), the areas where areas of posterior probability are greater than $50 \%$ AND areas of 
residential land use intersect in space (Fig 18), and where the areas defined in Fig 18 and the next weeks (Week 21, 2002) actual break and enters were located (Fig 19). Figure 20 shows the map that was used to determine the accuracy of the predictions for this period, and this map was replicated for all test points within this study.

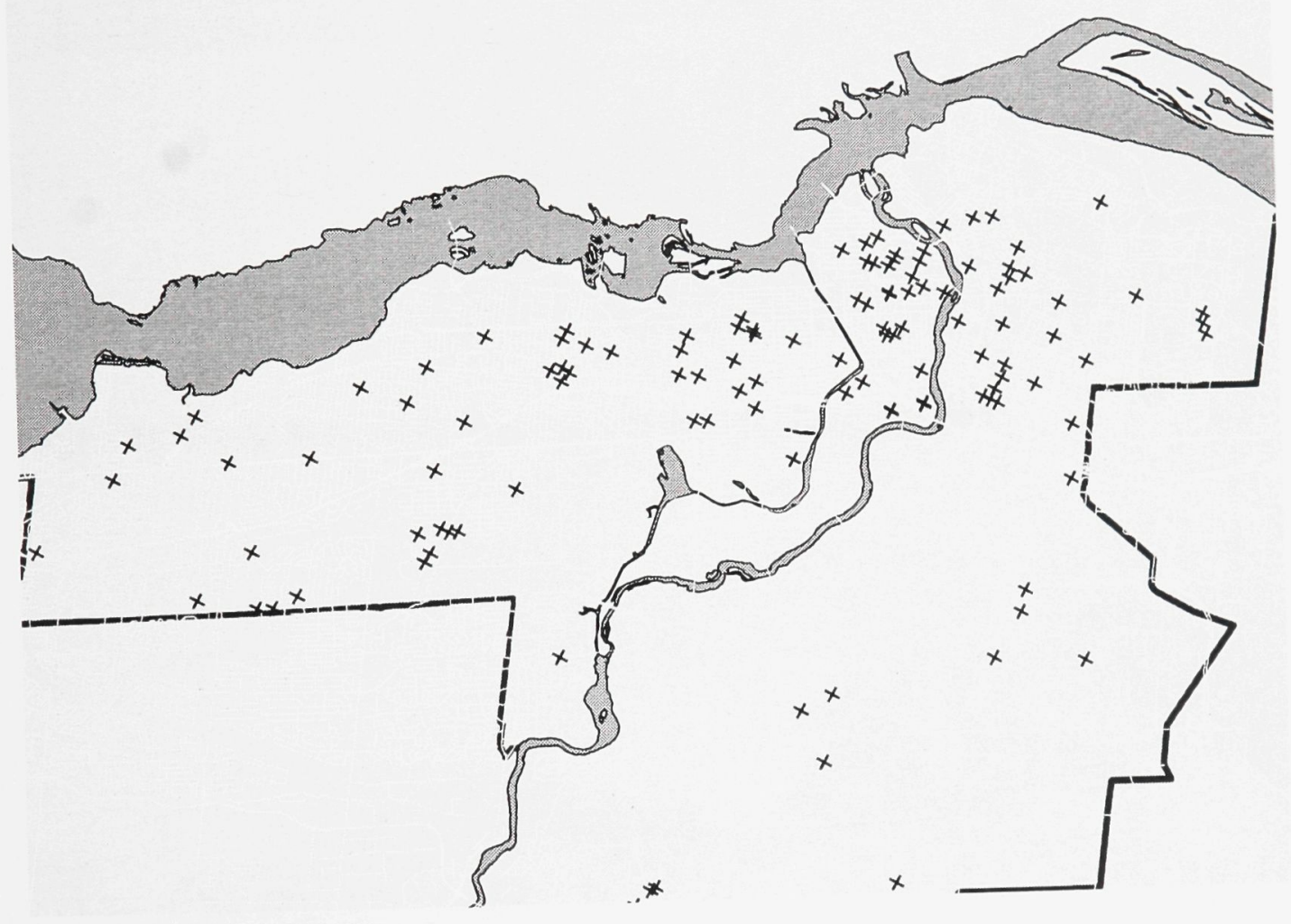

Figure 15 CPM Study Area and Training Data Locations for Week 202000 Test 


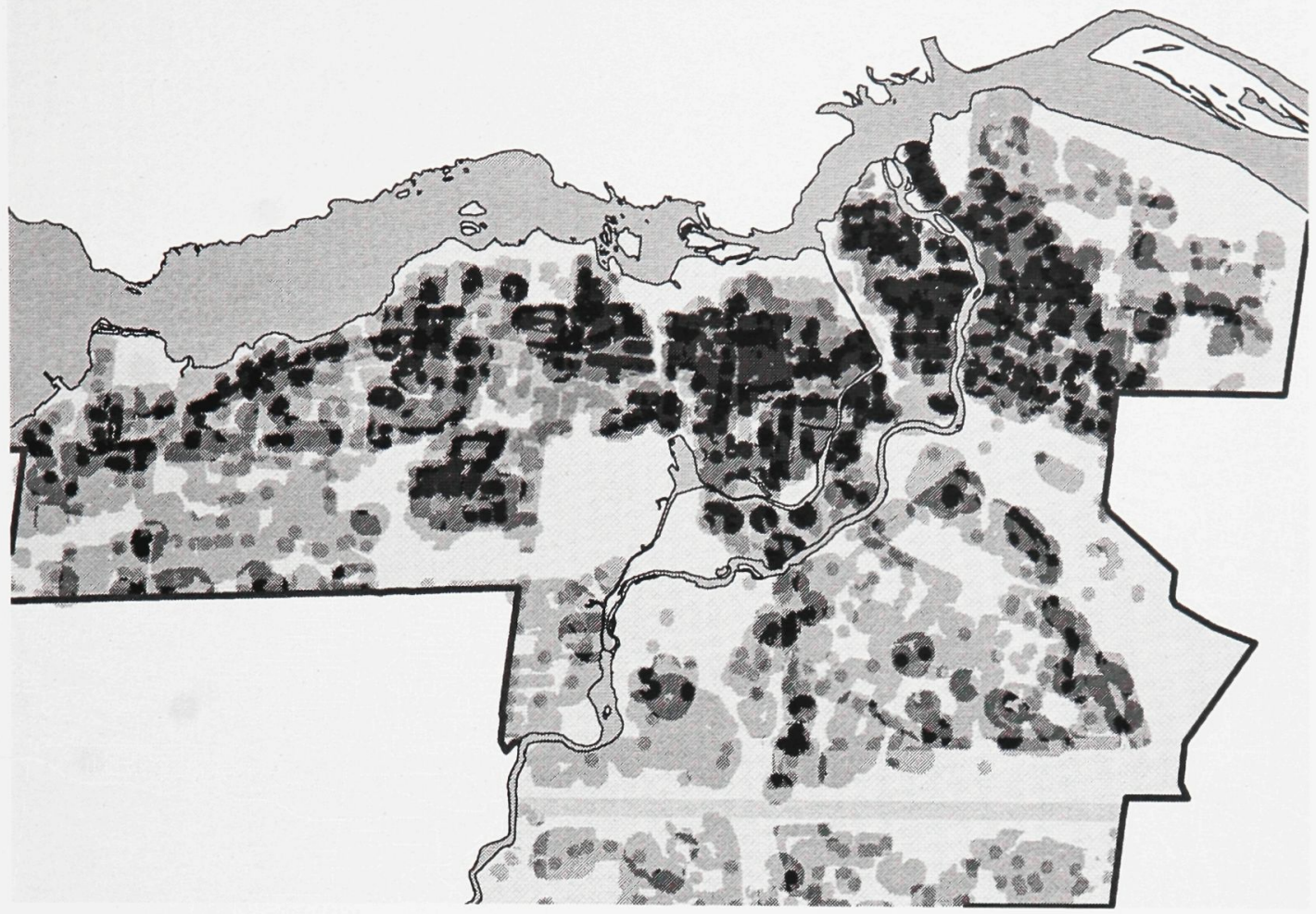

Figure 16 Study Area and CPM Predictions for Week 202000

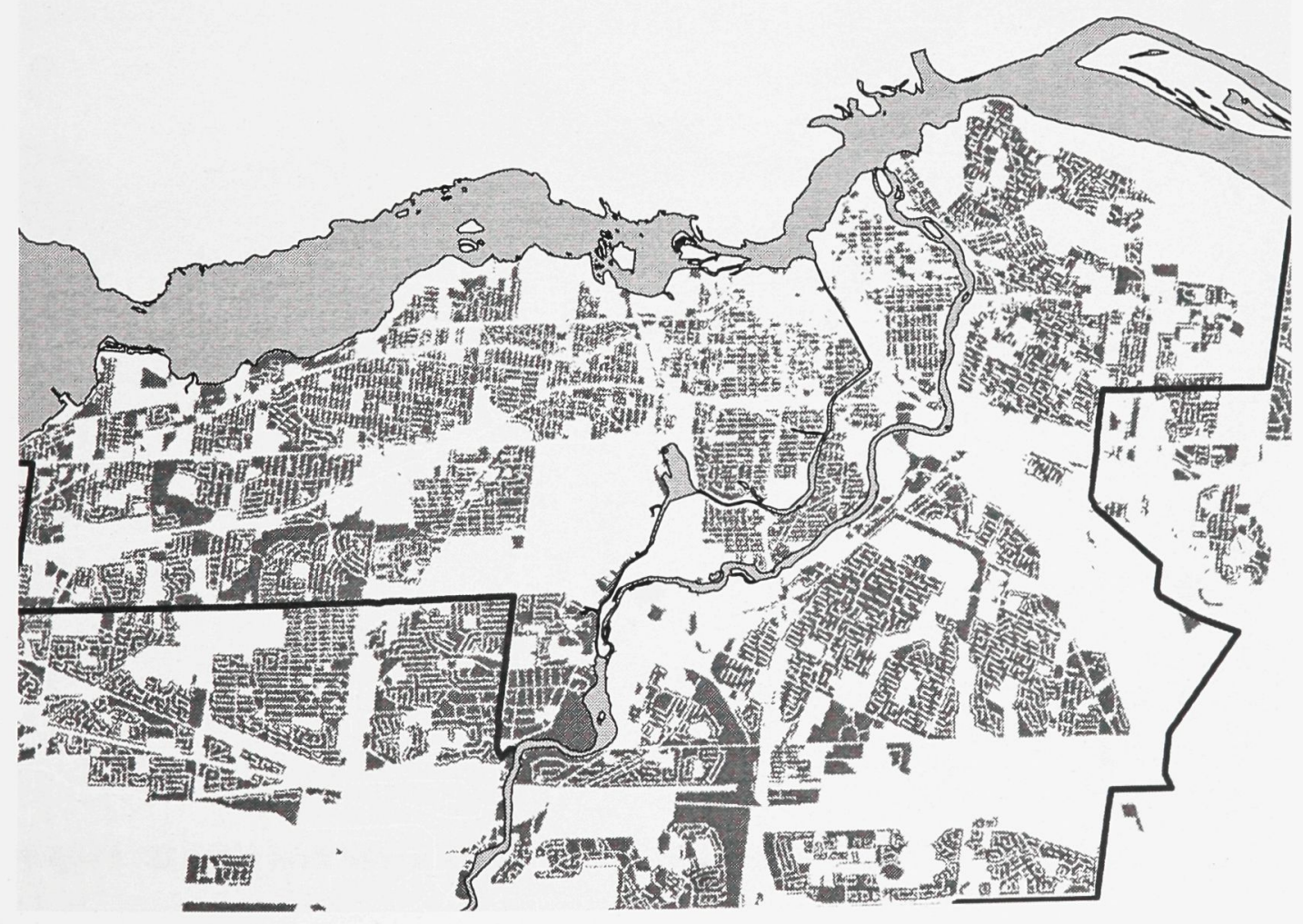

Figure 17 Study Area Showing Residential Land Use 


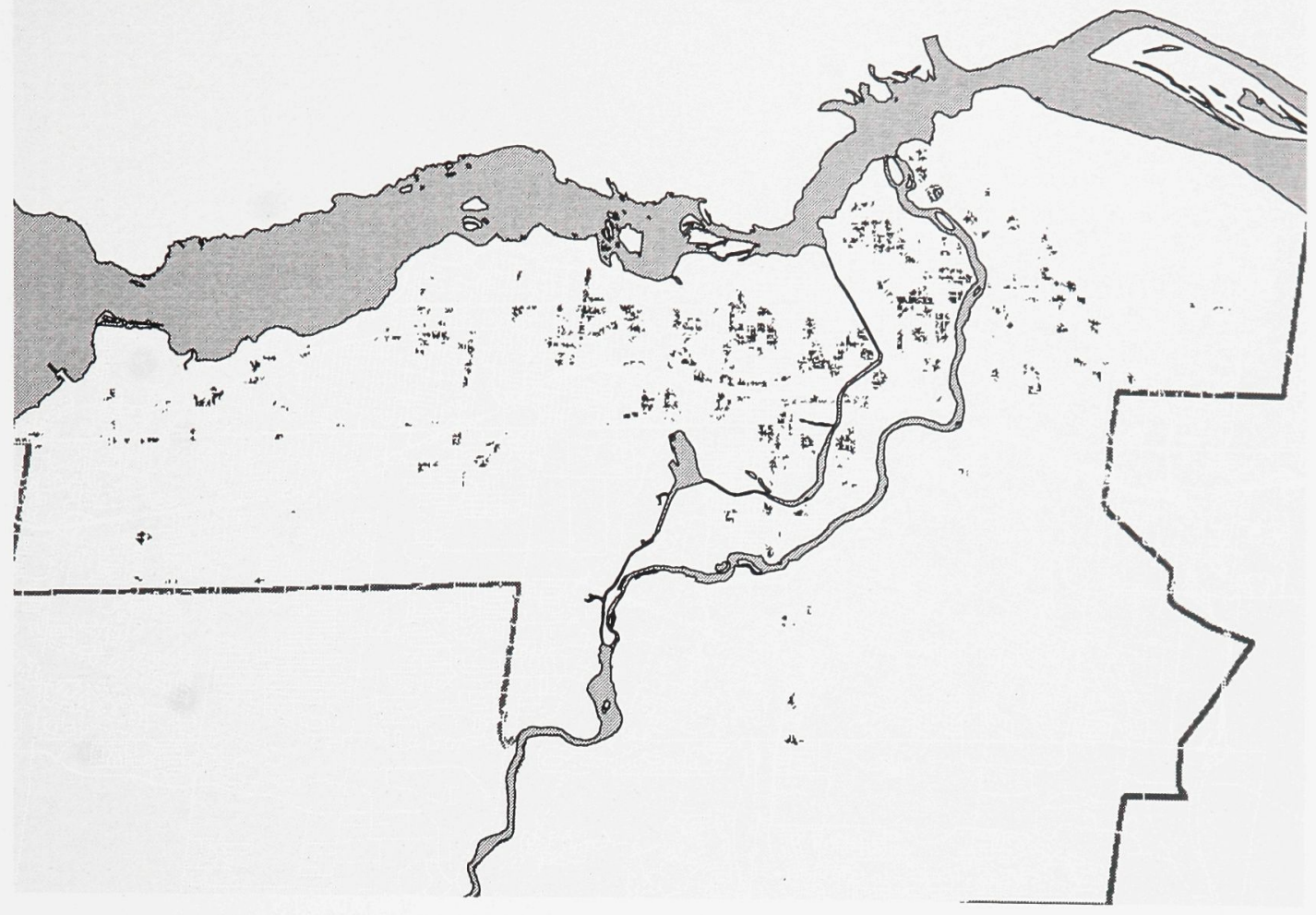

Figure 18 Study Area Showing Residential Land Use areas where CPM map > 50\% PP

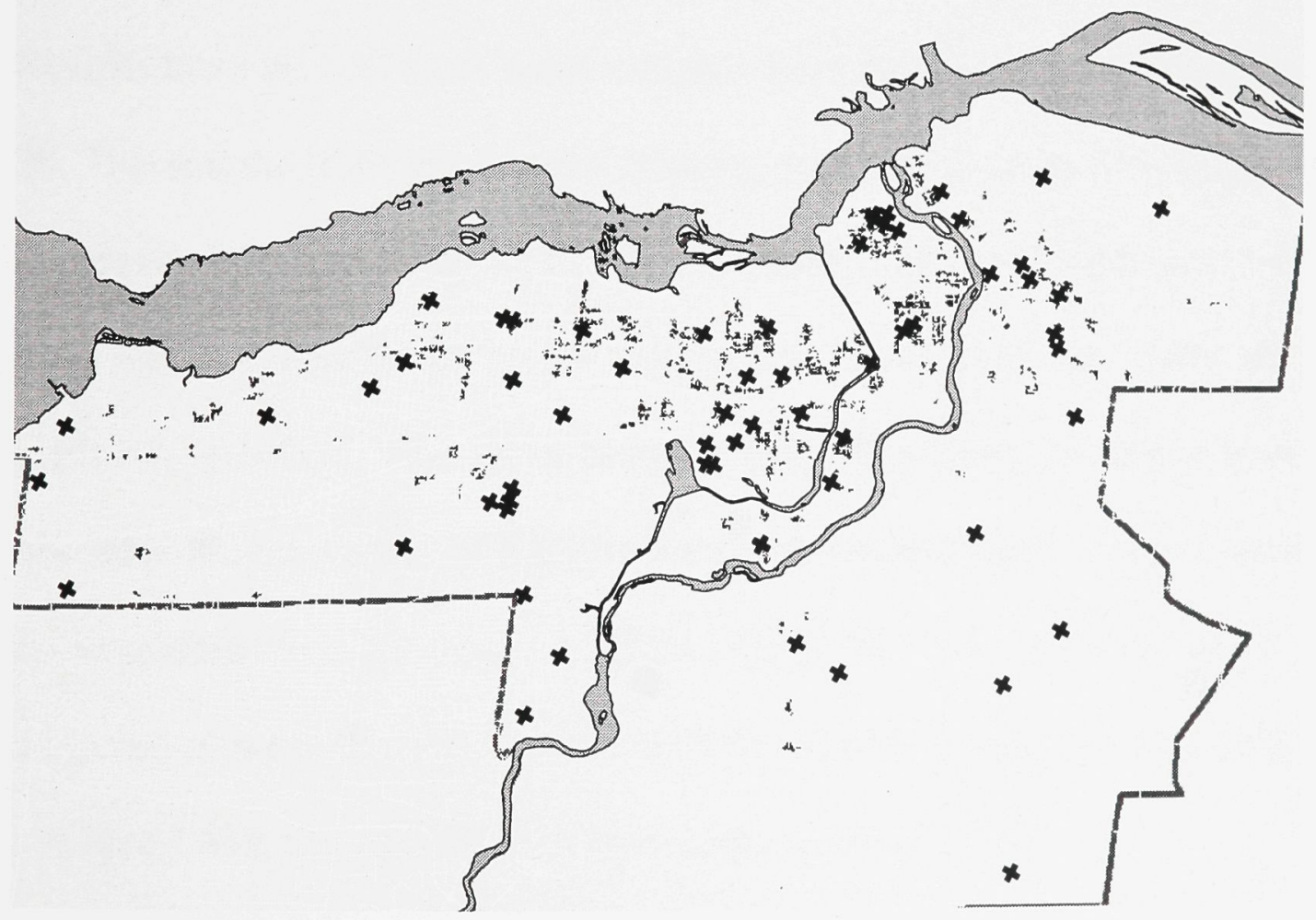

Figure 19 CPM and Week 202000 Test Data Locations 


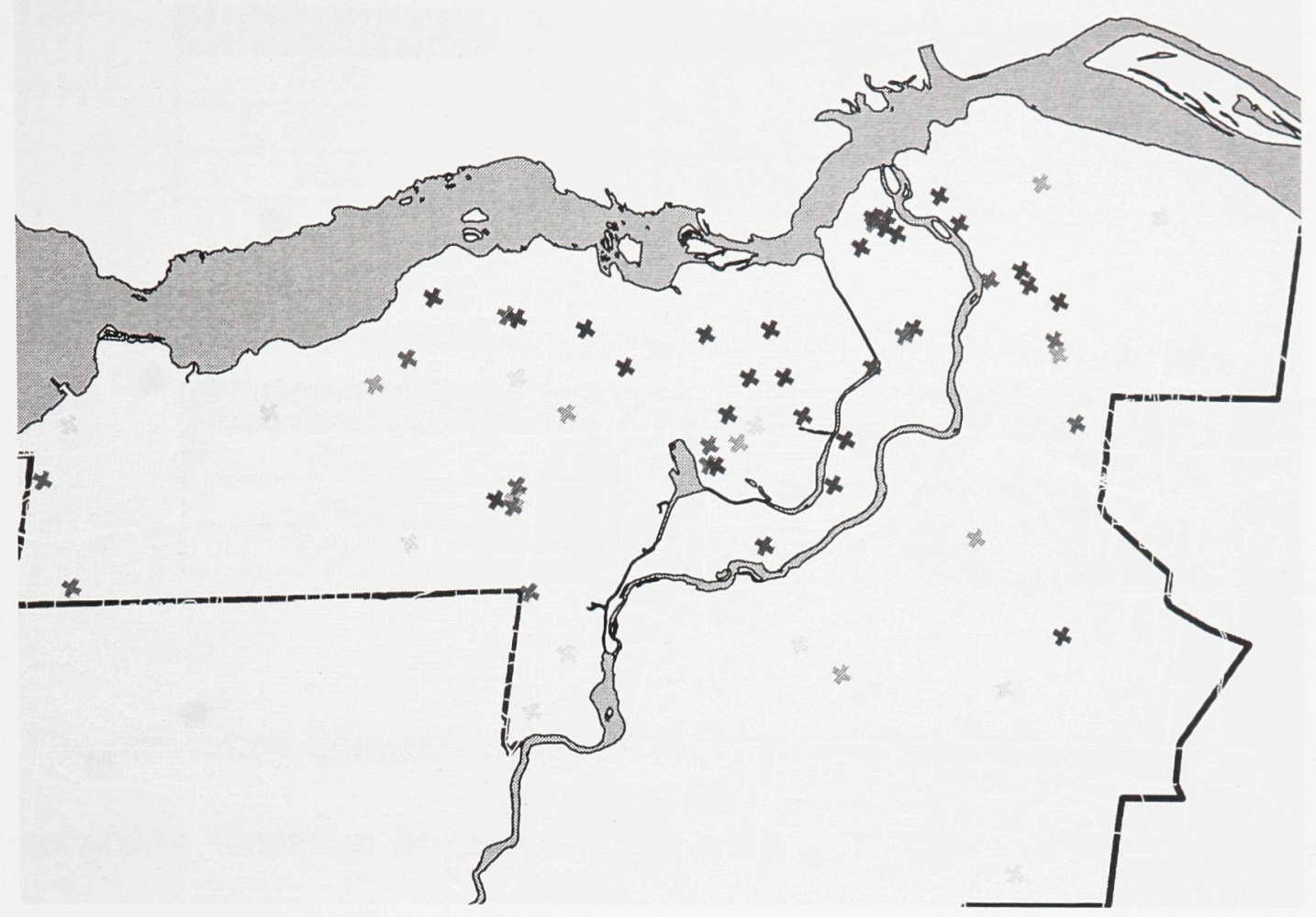

Figure 20 Post Probabilities of Week 202000 Test Locations

Results from all 120 tests were collated from the analyses as illustrated in Figure 20. The results from the 8-week training data test periods are summarized below for brevity and relevancy as the training data sets with less than 8 weeks of data were not considered to be as successful in meeting the goals of the second research question. The table below shows the maximum posterior probability of any known occurrence of B\&E in the week being tested, using 8 weeks worth of training data. For example, in 2001, Week 40, we observed that a "new" B\&E occurred at a point predicted in the CPM to have a posterior probability of $90.1 \%$.

- in that CPM, the MaxPP that was observed was $91.9 \%$. 
Table 4 Maximum Probability of points in week being tested (8-week training data)

Max PP (Test) Week 10 Week 20 Week 30 Week 40 Week 50

\begin{tabular}{|c|c|c|c|c|c|}
\hline 2000 & $46.3 \%$ & $82.1 \%$ & $94.7 \%$ & $68.1 \%$ & $79.8 \%$ \\
\hline 2001 & $62.6 \%$ & $60.2 \%$ & $63.3 \%$ & $90.1 \%$ & $51.7 \%$ \\
\hline 2002 & $57.4 \%$ & $62.7 \%$ & $61.4 \%$ & $59.6 \%$ & $56.6 \%$ \\
\hline
\end{tabular}

Table 5 Maximum Probability of CPM for test period (8-week training data)

\begin{tabular}{|c|c|c|c|c|c|}
\hline MaxPP (CPM) & Week 10 & Week 20 & Week 30 & Week 40 & Week 50 \\
\hline 2000 & 63.7 & 82.1 & 94.7 & 68.1 & 88.1 \\
\hline 2001 & 72.6 & 65.7 & 68.5 & 91.9 & 64.2 \\
\hline 2002 & 69.9 & 69.7 & 67.9 & 67.9 & 70.1 \\
\hline
\end{tabular}

The difference between the MaxPP (Test) and MaxPP CPM is an indicator of the reliability, therefore accuracy of the crime potential map that was produced. As is evident in the data, there was generally a good level of reliability in the output of the CPM versus the data in the week being tested. Based on these 8-week tests, there was rarely an instance where the difference between MaxPP (CPM) and MaxPP (Test) exceeded 15\% - OR where that difference would have put the MaxPP (Test) below the $50 \%$ posterior probability level - the exception being Week 10 in 2000. The complete set of results is supplied in the Appendix of this report.

The variability of the observed MaxPP (CPM) and MaxPP (Test) values from test to test indicate a good deal of variation in the predictive capability of the model as it was utilized. However, since all weeks made some sort of successful prediction (i.e. MaxPP $>50 \%$ ), the variation in MaxPP (CPM) is not wholly relevant. 


\section{$\underline{\text { Chapter VI - Conclusions }}$}

This goal of this thesis was to integrate the three key environmental criminology theories into a spatial predictive model to generate crime potential maps for residential break and enters. Rational Choice theory, Routine Activity theory and Crime Pattern theory were all examined in order to determine those particular land use types that seemed, as far as the literature was concerned, to be significant factors in the locations that motivated offenders choose to commit their crimes. These land uses and their factors included: proximity to commercial land use, proximity to vacant land/parkland, proximity to main transportation corridors, proximity to four-node intersections, urban trails and recreational land use.

The purpose of the crime potential map is to provide an illustration of likely areas that could be targeted given specific arrangements of these land use factors especially in those areas where several key land uses intersect and have a degree of interplay on each other. The hypothesis here is that, given the presence of any or all these factors in a particular place, it is more likely that the homes in this particular place provide a better opportunity for a motivated offender to commit a break and enter. Within the weights of evidence (WofE) model, these land uses were considered to be layers of evidence while known locations of break and enters were considered to be training data for the model. 
The research questions that were posed in this thesis address the specific arrangements of the identified land use factors that would generate a useful, effective and accurate crime potential map from the GIS-based weights of evidence model.

Using known locations of residential break and enters (training data) from a three year period (2000-2002), geospatial land use data (layers of evidence/fixed spatial effects) and the ArcView 3.2 Arc-WofE extension, a quasi-experimental testing framework was created to analyze the data and assess the outputs of a series of crime potential maps. Based on the WofE measure of $\mathrm{SC}$ (Studentized contrast), an optimum level of "proximity" was calculated for each of the six land use types that were identified and a series of test runs for potential were conducted to identify the optimum arrangements for both the training data and the layers of evidence that accounted for changes over time and provided an accurate prediction for the next week's break and enter locations.

The outcomes of this testing indicated that, more often that not, about eight weeks training data were required to prime the model, using the specific proximities for each layer of evidence, in order to generate a crime potential map that a. had at least a few cells in the crime potential map with a posterior probability measure (MaxPP) that exceeded $60 \%$ to assess the utility and effectiveness of the model, and b. showed that at least one location in the next 
week's break and enter occurrences was located in an area of high probability based on the test run and the resulting crime potential map.

Given the inclusion of eight weeks of training data preceding the prediction week and the specific arrangements of the layers of evidence that were used, this process showed that these goals were met in almost every test period that was observed. In fact, there were several test periods (Weeks 20 and 30 in 2000; Week 40 in 2001) that provided highly accurate predictions in that several of the next week's break and enter occurrences were located in areas of probability that exceeded $90 \%$. In fact, these tests showed that at least one future occurrence fell within the area of greatest posterior probability identified in the crime potential map. Additionally, these areas that exceeded $90 \%$ posterior probability identified less than $1 \%$ of the landmass within the study area in these cases, allowing the user to easily narrow down these areas of high probability and making for some very effective crime potential maps.

Given this range of success and stability of the predictions that were generated using this model and with this data, it can be concluded that the research goals were conclusively and undeniably met. 


\section{Critical Assessment of CPM}

The issue of environmental determinism has become an issue in the quantitative spatial analysis of crime using these data-driven predictive methods. The question of determinism can be defined as "cause and effect" and in this research the issue of concern is that the environment will determine how an individual will act in that environment.

There is certainly a great danger in leaping to a conclusion such as: given the right set of circumstances, a motivated offender will commit a crime if the opportunity exists. After careful consideration of the deterministic bent that this thesis could have taken, it was recommended that I pay particular attention to using non-deterministic language in the body of this thesis as well as recognize the pitfalls of determinism in all stages of my analysis.

The three key theories of environmental criminology that were cited in this report do tread on the razor's edge of determinism, but this danger can be minimized in ensuring that, while recognizing that the physical environment can be considered to be an etiological factor in where crime occurs, it is far from being wholly causal.

One of the main precepts in this research and in my argument in general is that the focus is on the crime event as opposed to being on the offender. This notion 
is supported by Brantingham and Brantingham's (1981) criticism of the positivistic nature of spatial crime analysis research that had been popularized starting in the era of Shaw and McKay and ending in the early 1980s. As opposed to looking at the characteristics of large aggregate areas, using aggregate vital statistics and aggregate crime statistics, they recommended an approach that drilled down to the local, site-specific characteristics of crime. This is the approach that this research endeavours to follow. This research does not seek to provide a causal explanation as to why crime occurs where it does, but does seek to find a link between the immediate environmental factors and the occurrence of crime that is supported by crime pattern theory, routine activity theory and rational choice theory. I believe that within the scope and scale of this project, I have succeeded in this goal. I firmly believe that these links identified in the literature do exist and have been supported by the analysis contained in this report, amongst others. The opportunity for offenders to commit break and enters does seem to be greater when there are more of these particular land uses in close proximity to suitable targets. This is not to suggest that if all the specified environmental cues are present at a particular place and time that a motivated offender WILL take advantage of the opportunity presented to commit a crime at that place and time - this merely suggests a greater potential could exist in these places at these times. 
Appendix A - Wofe Results Data Tables

\begin{tabular}{|c|c|c|c|c|c|c|c|c|}
\hline Run ld & Weeks & \# Weeks & Against & Year & Num TP $/ M$ & Max.PP (Grid) M & Max.PP (Obs.) & Prior Prob. \\
\hline 0_05 & 9 & 1 & 10 & 2000 & 13 & 6.8 & 5.7 & 0.4 \\
\hline 0_10 & 19 & 1 & 20 & 2000 & 35 & 71.8 & 71.8 & 1 \\
\hline $0 \_15$ & 29 & 1 & 30 & 2000 & 56 & 41 & 30.8 & 1.6 \\
\hline 0_20 & 39 & 1 & 40 & 2000 & 29 & 10.6 & 10.1 & 0.9 \\
\hline 0_25 & 49 & 1 & 50 & 2000 & 35 & 28.5 & 24.4 & 1 \\
\hline 0_04 & 8 thru 9 & 2 & 10 & 2000 & 32 & 29.2 & 17.6 & 0.9 \\
\hline 0_09 & 18 thru 19 & 2 & 20 & 2000 & 65 & 78.9 & 78.9 & 1.9 \\
\hline $0 \_14$ & 28 thru 29 & 2 & 30 & 2000 & 119 & 61.4 & 61.3 & 3.5 \\
\hline 0_19 & 38 thru 39 & 2 & 40 & 2000 & 76 & 38.1 & 38.1 & 2.2 \\
\hline 0_24 & 48 thru 49 & 2 & 50 & 2000 & 65 & 31.2 & 23.4 & 1.9 \\
\hline 0_03 & 7 thru 9 & 3 & 10 & 2000 & 40 & 27.3 & 18.6 & 1.2 \\
\hline 0_08 & 17 thru 19 & 3 & 20 & 2000 & 83 & 79.7 & 79.7 & 2.4 \\
\hline 0_13 & 27 thru 29 & 3 & 30 & 2000 & 180 & 81.6 & 81.6 & 5.3 \\
\hline 0_18 & 37 thru 39 & 3 & 40 & 2000 & 169 & 62.7 & 62.7 & 5 \\
\hline 0_23 & 47 thru 49 & 3 & 50 & 2000 & 103 & 52.2 & 42.8 & 3 \\
\hline 0_02 & 6 thru 9 & 4 & 10 & 2000 & 48 & 27.5 & 19.8 & 1.4 \\
\hline 0_07 & 16 thru 19 & 4 & 20 & 2000 & 93 & 77 & 77 & 2.7 \\
\hline 0_12 & 26 thru 29 & 4 & 30 & 2000 & 218 & 84.8 & 84.8 & 6.4 \\
\hline 0_17 & 36 thru 39 & 4 & 40 & 2000 & 150 & 46 & 46 & 4.4 \\
\hline $0 \_22$ & 46 thru 49 & 4 & 50 & 2000 & 153 & 57.8 & 50.9 & 4.5 \\
\hline 0_01 & 5 thru 9 & 5 & 10 & 2000 & 68 & 42.2 & 28.9 & 2 \\
\hline 0_06 & 15 thru 19 & 5 & 20 & 2000 & 105 & 78.8 & 78.8 & 3.1 \\
\hline 0_11 & 25 thru 29 & 5 & 30 & 2000 & 260 & 87.6 & 87.6 & 7.6 \\
\hline $0 \_16$ & 35 thru 39 & 5 & 40 & 2000 & 184 & 50.5 & 50.5 & 5.4 \\
\hline $0 \_21$ & 45 thru 49 & 5 & 50 & 2000 & 190 & 72.5 & 63.7 & 5.6 \\
\hline $0 \_1$ & 4 thru 9 & 6 & 10 & 2000 & 84 & 43.3 & 29.5 & 2.5 \\
\hline $0 \_2$ & 14 thru 19 & 6 & 20 & 2000 & 122 & 78.3 & 78.3 & 3.6 \\
\hline $0 \_3$ & 24 thru 29 & 6 & 30 & 2000 & 313 & 90.5 & 90.5 & 9.2 \\
\hline $0 \_4$ & 34 thru 39 & 6 & 40 & 2000 & 209 & 56.2 & 56.2 & 6.1 \\
\hline $0 \_5$ & 44 thru 49 & 6 & 50 & 2000 & 229 & 75.8 & 67.8 & 6.7 \\
\hline $0 \_6$ & 3 thru 9 & 7 & 10 & 2000 & 95 & 54.4 & 37.1 & 2.8 \\
\hline $0 \_7$ & 13 thru 19 & 7 & 20 & 2000 & 135 & 80.4 & 80.4 & 4 \\
\hline $0 \_8$ & 23 thru 29 & 7 & 30 & 2000 & 372 & 92.9 & 92.9 & 11 \\
\hline $0 \_9$ & 33 thru 39 & 7 & 40 & 2000 & 255 & 57.6 & 57.6 & 7.5 \\
\hline $0 \_10$ & 43 thru 49 & 7 & 50 & 2000 & 297 & 84.6 & 76.1 & 8.2 \\
\hline 0_11 & 2 thru 9 & 8 & 10 & 2000 & 111 & 63.7 & 46.3 & 3.3 \\
\hline $0 \_12$ & 12 thru 19 & 8 & 20 & 2000 & 149 & 82.1 & 82.1 & 4.4 \\
\hline $0 \_13$ & 22 thru 29 & 8 & 30 & 2000 & 412 & 94.7 & 94.7 & 12.1 \\
\hline $0 \_14$ & 32 thru 39 & 8 & 40 & 2000 & 310 & 68.1 & 68.1 & 9.1 \\
\hline $0 \quad 15$ & 42 thru 49 & 8 & 50 & 2000 & 321 & 88.1 & 79.8 & 9.4 \\
\hline 1_05 & 9 & 1 & 10 & 2001 & 23 & 6.6 & 6.6 & 0.7 \\
\hline 1_10 & 19 & 1 & 20 & 2001 & 38 & 14.3 & 14.3 & 1.1 \\
\hline $1 \_15$ & 29 & 1 & 30 & 2001 & 46 & 39.4 & 37 & 2.7 \\
\hline 1_20 & 39 & 1 & 40 & 2001 & 40 & 87.1 & 84.1 & 1.2 \\
\hline 1_25 & 49 & 1 & 50 & 2001 & 38 & 14 & 8.8 & 1.1 \\
\hline 1_04 & 8 thru 9 & 2 & 10 & 2001 & 63 & 24.4 & 24.4 & 1.9 \\
\hline
\end{tabular}




\begin{tabular}{|c|c|c|c|c|c|c|c|c|}
\hline 1_09 & 18 thru 19 & 2 & 20 & 2001 & 75 & 22.2 & 22.2 & 2.2 \\
\hline 1_14 & 28 thru 29 & 2 & 30 & 2001 & 91 & 39.4 & 37 & 2.7 \\
\hline 1_19 & 38 thru 39 & 2 & 40 & 2001 & 93 & 79.4 & 76.3 & 2.7 \\
\hline 1_24 & 48 thru 49 & 2 & 50 & 2001 & 66 & 25.3 & 16.1 & 1.9 \\
\hline 1_03 & 7 thru 9 & 3 & 10 & 2001 & 96 & 42.9 & 31.7 & 2.8 \\
\hline 1_08 & 17 thru 19 & 3 & 20 & 2001 & 102 & 21.6 & 16.8 & 1.1 \\
\hline 1_13 & 27 thru 29 & 3 & 30 & 2001 & 136 & 48.2 & 40.3 & 4 \\
\hline 1_18 & 37 thru 39 & 3 & 40 & 2001 & 163 & 79.1 & 78.6 & 4.8 \\
\hline 1_23 & 47 thru 49 & 3 & 50 & 2001 & 96 & 40.4 & 36.5 & 2.8 \\
\hline 1_02 & 6 thru 9 & 4 & 10 & 2001 & 117 & 47.9 & 42 & 3.4 \\
\hline 1_07 & 16 thru 19 & 4 & 20 & 2001 & 129 & 35.7 & 35.7 & 3.9 \\
\hline 1_12 & 26 thru 29 & 4 & 30 & 2001 & 174 & 61.6 & 60 & 5.1 \\
\hline 1_17 & 36 thru 39 & 4 & 40 & 2001 & 211 & 83.4 & 80.7 & 6.2 \\
\hline 1_22 & 46 thru 49 & 4 & 50 & 2001 & 129 & 44.3 & 41.4 & 3.8 \\
\hline 1_01 & 5 thru 9 & 5 & 10 & 2001 & 133 & 53.9 & 43 & 3.9 \\
\hline 1_06 & 15 thru 19 & 5 & 20 & 2001 & 151 & 44.3 & 44.3 & 4.4 \\
\hline 1_11 & 25 thru 29 & 5 & 30 & 2001 & 208 & 65.2 & 58 & 6.1 \\
\hline 1_16 & 35 thru 39 & 5 & 40 & 2001 & 264 & 87.1 & 85 & 7.7 \\
\hline 1_21 & 45 thru 49 & 5 & 50 & 2001 & 167 & 46.1 & 40.9 & 4.9 \\
\hline 1_1 & 4 thru 9 & 6 & 10 & 2001 & 149 & 60.9 & 50.8 & 4.4 \\
\hline $1 \_2$ & 14 thru 19 & 6 & 20 & 2001 & 173 & 48.3 & 48.3 & 5.1 \\
\hline 1_3 & 24 thru 29 & 6 & 30 & 2001 & 250 & 62.2 & 56 & 7.3 \\
\hline 1_4 & 34 thru 39 & 6 & 40 & 2001 & 313 & 87.5 & 84.5 & 9.2 \\
\hline $1 \_5$ & 44 thru 49 & 6 & 50 & 2001 & 227 & 55.5 & 49.7 & 6.7 \\
\hline 1_6 & 3 thru 9 & 7 & 10 & 2001 & 179 & 65.6 & 55.5 & 5.3 \\
\hline 1_7 & 13 thru 19 & 7 & 20 & 2001 & 246 & 67.9 & 62.4 & 7.2 \\
\hline $1 \_8$ & 23 thru 29 & 7 & 30 & 2001 & 283 & 67.3 & 62.4 & 8.3 \\
\hline 1_9 & 33 thru 39 & 7 & 40 & 2001 & 283 & 60.5 & 56.1 & 8.3 \\
\hline 1_10 & 43 thru 49 & 7 & 50 & 2001 & 241 & 56 & 46.9 & 7.1 \\
\hline 1_11 & 2 thru 9 & 8 & 10 & 2001 & 209 & 72.6 & 62.6 & 6.1 \\
\hline 1_12 & 12 thru 19 & 8 & 20 & 2001 & 236 & 65.7 & 60.2 & 6.9 \\
\hline 1_13 & 22 thru 29 & 8 & 30 & 2001 & 305 & 68.5 & 63.3 & 8.9 \\
\hline 114 & 32 thru 39 & 8 & 40 & 2001 & 442 & 91.9 & 90.1 & 13 \\
\hline 2_05 & 9 & 1 & 10 & 2002 & 40 & 6.9 & 6.9 & 1.2 \\
\hline 2_10 & 19 & 1 & 20 & 2002 & 32 & 10.3 & 9.8 & 0.9 \\
\hline 2_15 & 29 & 1 & 30 & 2002 & 62 & 19.9 & 19.9 & 1.8 \\
\hline 2_20 & 39 & 1 & 40 & 2002 & 25 & 5 & 4.3 & 0.7 \\
\hline 2_25 & 49 & 1 & 50 & 2002 & 28 & 19.1 & 14.6 & 0.8 \\
\hline 2_04 & 8 thru 9 & 2 & 10 & 2002 & 71 & 19.3 & 18.9 & 2.1 \\
\hline 2_09 & 18 thru 19 & 2 & 20 & 2002 & 77 & 33.8 & 25.7 & 2.3 \\
\hline 2_14 & 28 thru 29 & 2 & 30 & 2002 & 107 & 31.4 & 29.4 & 3.1 \\
\hline 2_19 & 38 thru 39 & 2 & 40 & 2002 & 63 & 20.7 & 19.2 & 1.9 \\
\hline $2 \_24$ & 48 thru 49 & 2 & 50 & 2002 & 48 & 24.7 & 19.1 & 0.2 \\
\hline 2_03 & 7 thru 9 & 3 & 10 & 2002 & 112 & 30.7 & 29.4 & 3.3 \\
\hline 2_08 & 17 thru 19 & 3 & 20 & 2002 & 109 & 45.1 & 35.6 & 3.2 \\
\hline 2_13 & 27 thru 29 & 3 & 30 & 2002 & 179 & 52.5 & 52.5 & 5.3 \\
\hline 2_18 & 37 thru 39 & 3 & 40 & 2002 & 95 & 29.3 & 26.3 & 2.8 \\
\hline $2 \_23$ & 47 thru 49 & 3 & 50 & 2002 & 70 & 39.5 & 30.2 & 2.1 \\
\hline 2_02 & 6 thru 9 & 4 & 10 & 2002 & 154 & 49.4 & 41.7 & 4.5 \\
\hline 2_07 & 16 thru 19 & 4 & 20 & 2002 & 133 & 48.1 & 40.7 & 3.9 \\
\hline
\end{tabular}




\begin{tabular}{|ccccccccc} 
2_12 & 26 thru 29 & 4 & 30 & 2002 & 210 & 58.4 & 58.4 & 6.2 \\
2_17 & 36 thru 39 & 4 & 40 & 2002 & 138 & 36.3 & 33.4 & 4 \\
2_22 & 46 thru 49 & 4 & 50 & 2002 & 100 & 54.9 & 40.4 & 2.9 \\
2_01 & 5 thru 9 & 5 & 10 & 2002 & 189 & 47.4 & 41.9 & 5.5 \\
2_06 & 15 thru 19 & 5 & 20 & 2002 & 168 & 63.2 & 50.6 & 4.9 \\
2_11 & 25 thru 29 & 5 & 30 & 2002 & 261 & 65.8 & 65.6 & 7.7 \\
2_16 & 35 thru 39 & 5 & 40 & 2002 & 179 & 43.6 & 43.2 & 5.3 \\
2_21 & 45 thru 49 & 5 & 50 & 2002 & 128 & 65.2 & 48.2 & 3.8 \\
2_1 & 4 thru 9 & 6 & 10 & 2002 & 228 & 55 & 49.6 & 6.7 \\
2_2 & 14 thru 19 & 6 & 20 & 2002 & 205 & 65.2 & 56 & 6 \\
2_3 & 24 thru 29 & 6 & 30 & 2002 & 296 & 70.3 & 70.3 & 8.7 \\
2_4 & 34 thru 39 & 6 & 40 & 2002 & 223 & 52.6 & 52.1 & 6.5 \\
2_5 & 44 thru 49 & 6 & 50 & 2002 & 159 & 67.5 & 60 & 4.7 \\
2_6 & 3 thru 9 & 7 & 10 & 2002 & 252 & 62.2 & 51.9 & 7.4 \\
2_7 & 13 thru 19 & 7 & 20 & 2002 & 233 & 67.4 & 59.5 & 6.8 \\
2_8 & 23 thru 29 & 7 & 30 & 2002 & 337 & 75.7 & 73.3 & 9.9 \\
2_9 & 33 thru 39 & 7 & 40 & 2002 & 283 & 60.5 & 56.1 & 8.3 \\
2_10 & 43 thru 49 & 7 & 50 & 2002 & 179 & 69.1 & 57.1 & 5.3 \\
2_15 & 42 thru 49 & 8 & 50 & 2002 & 217 & 70.1 & 56.6 & 6.4 \\
2_11 & 2 thru 9 & 8 & 10 & 2002 & 279 & 69.9 & 57.4 & 8.2 \\
2_12 & 12 thru 19 & 8 & 20 & 2002 & 252 & 69.7 & 62.7 & 7.4 \\
2_13 & 22 thru 29 & 8 & 30 & 2002 & 327 & 67.9 & 61.4 & 9.6 \\
2_14 & 32 thru 39 & 8 & 40 & 2002 & 327 & 67.9 & 59.6 & 9.6 \\
2_15 & 42 thru 49 & 8 & 50 & 2002 & 217 & 70.1 & 56.6 & 6.4 \\
\hline
\end{tabular}




\section{Bibliography}

Anselin, L., J. Cohen, D. Cook, W. Gorr, G. Tita (2002). Spatial Analysis of Crime. Measurement and Analysis of Crime and Justice: Criminal Justice 2000 4, pp213-262 (National Institute of Justice)

Beavon, D.K., P.J. Brantingham and P.L. Brantingham (1994). "The Influence of Street Networks on the Patterning of Property Offences" in R.V. Clarke (Ed), Crime Prevention Studies, Volume 2. Monsey, N.Y. Criminal Justice Press.

Bichler-Robertson, Gisela and Melissa Johnson (2001). Connecting Environmental Cues to Commercial Burglary Concentrations: Combining Theory and Practice into a blended approach. Paper presented at the $10^{\text {th }}$ International Seminar on Environmental Criminology and Crime Analysis. June 18 2001.

Block, Richard L. and Carolyn R. Block (1995). "Space, Place and Crime: Hot Spot Areas and Hot Places of Liquor-Related Crime in John E. Eck and David Weisburd (Eds.) Crime and Place: Crime Prevention Studies Volume 4. Monsey, N.Y., Criminal Justice Press.

Bonham-Carter, Graeme F. (1994). "Geographic Information Systems for Geoscientists: Modelling with GIS" Great Britain, Elsevier Science. 
Bowers, K.D., Johnson, S.D., Pease, K. (2004) "Prospective Hotspotting: the Future of Crime Mapping?" British Journal of Criminology, 44, pp. 641-658.

Brantingham, Paul J. and Patricia L. Brantingham (1981). Environmental Criminology. Beverley Hills. Sage Publications.

Brantingham, Paul J. and Patricia L. Brantingham (1984) Patterns in Crime. New York, Macmillan.

Brantingham, Paul J. and Patricia L. Brantingham (1991). Environmental Criminology (reissue). Prospect Heights, Waveland Press.

Buerger, M.E, E.G. Cohn and A.J. Petrosino (1995). "Defining the "Hotspots of Crime': Operationalizing Theoretical Concepts for Field Research" in John E. Eck and David Weisburd (Eds.) Crime and Place: Crime Prevention Studies Volume 4. Monsey, N.Y., Criminal Justice Press.

Bursik, R.J. and H.G. Grasmick (1993). Neighborhoods and Crime. New York, Lexington Books.

Clarke, Ronald V. (1997). "Part 1: Introduction" in Ronald V. Clarke Situational Crime Prevention: Successful Case Studies. Albany, N.Y., Harrow and Heston. 
Cohen, L.E. and M. Felson (1979). "Social Change and Crime Rate Trends: A Routine Activity Approach" American Sociological Review 44, pp588-605

Cornish, D. and R.V. Clarke, Eds. (1986). The Reasoning Criminal: Rational Choice Perspectives on Offending. New York, Springer-Verlang.

Davidson, R.N. (1981). Crime and Environment. London, Croom Helm.

Eck, John E. and Weisburd, David (1995). "Crime Places in Crime Theory" in John E. Eck and David Weisburd (Eds.) Crime and Place: Crime Prevention Studies Volume 4. Monsey, N.Y., Criminal Justice Press.

Felson, Marcus (1998). Crime \& Everyday Life. $2^{\text {nd }}$ Edition. Thousand Oaks, Ca. Pine Forge Press.

Gorr, W and A. Olligschlaeger (2000), "Assessment of Crime Forecasting Accuracy on Deployment of Police" International Journal of Forecasting, Special Issue of Crime Forecasting.

Harries, K.D. (1999). Mapping Crime: Principle and Practice. Wahsington, D.C. National Institute of Justice.

Herbert, David T. (1982). The Geography of Urban Crime. London, Longman. 
Herbert, David T. (1989). "Crime and Place: An Introduction" in David J. Evans and David T. Herbert (Eds.), The Geography of Crime. London, Routledge.

Hesseling, R. (1992). "Using Data in Offender Mobility in Ecological Research". Journal of Quantitative Criminology. 8, pp.95-112.

Jeffrey, C.R. (1971) Crime Prevention Through Environmental Design. Beverley Hills, Sage Publications.

Kemp, L.D., Bonham-Carter, G.F., Raines, G.L and Looney, C.G. (2001). "ArcSDM: ArcView extension for spatial data modelling using weights of evidence, logistic regression, fuzzy logic and neural network analysis" http://ntserv.gis.nrcan.gc.ca/sdm/

Newman, O. (1972). Defensible Space. New York, Macmillan.

Rengert, G. (1989). "Behavioural Geography and Criminal Behaviour" in David J.

Evans and David T. Herbert (Eds.), The Geography of Crime. London, Routledge.

Rengert, G. and J. Wasilchick (2000). Suburban Burglary: A Tale of Two Suburbs. $2^{\text {nd }}$ Edition. Springfield, Illinois. Charles C. Thomas. 
Rossmo, D. Kim (2000). Geographic Profiling. Boca Raton. CRC Press.

Shaw C.R. and H.D. McKay (1942). Juvenile Delinquency and Urban Areas. Chicago, University of Chicago Press.

Sherman, L.W. (1995) "Hotspots of Crime and Criminal Careers of Places" in John E. Eck and David Weisburd (Eds.) Crime and Place: Crime Prevention Studies Volume 4. Monsey, N.Y., Criminal Justice Press.

Taylor ,R.B and S. Gottfredson (1986). "Environmental Design, crime and crime prevention: an examination of community dynamics" in A.J. Reiss and M. Tonry (Eds.) Communities and Crime. Crime and Justice: A Review of Research Vol 8. Chicago, University of Chicago Press.

Taylor, R.B. (1998). "Crime and Small Scale Places: What we Know, What We Can Prevent and What Else We Need to Know". Crime and Place: Plenary Papers of the 1997 Conference on Criminal Justice Research and Evaluation. July 1998, National Institute of Justice.

Weisburd, David and Tom McEwen (1998). "Crime Mapping and Crime Prevention" in David Weisburd and Tom McEwen (Eds.), Crime Mapping and 
Crime Prevention: Crime Prevention Studies Volume 8. Monsey, N.Y., Criminal Justice Press.

Weisburd, David, L.. Maher and L.W. Sherman (1992) "Contrasting Crime General and Crime Specific Theory: The Case of Crime Hot Spots" in F. Adler and W.S. Laufer (Eds.) Advances in Criminological Theory, Volume 4. New Brunswick, N.J., Transaction Publishers.

White, G.F. (1990). "Neighborhood Permeability and Burglary Rates". Justice Quarterly. 7, pp. 57-68.

Wilson, J.Q. and G.L. Kelling (1982). "Broken Windows". The Atlantic Monthly (March) 29-38.

Wright, R. and R.H. Logie (1988) "How Young House Burglars Choose Targets". The Howard Journal of Criminal Justice" 27. pp.92-104. 